\title{
Stabilization of apoptotic cells: generation of zombie cells
}

\author{
M Oropesa-Ávila ${ }^{1}$, Y Andrade-Talavera' ${ }^{2}$ J Garrido-Maraver ${ }^{1}$, MD Cordero ${ }^{3}$, M de la Mata ${ }^{1}$, D Cotán ${ }^{1}$, MV Paz ${ }^{1}$, AD Pavón ${ }^{1}$, \\ E Alcocer-Gómez ${ }^{1}$, I de Lavera ${ }^{1}$, R Lema ${ }^{1}$, AP Zaderenko ${ }^{4}$, A Rodríguez-Moreno ${ }^{2}$ and JA Sánchez-Alcázar ${ }^{*, 1}$
}

Apoptosis is characterized by degradation of cell components but plasma membrane remains intact. Apoptotic microtubule network (AMN) is organized during apoptosis forming a cortical structure beneath plasma membrane that maintains plasma membrane integrity. Apoptotic cells are also characterized by high reactive oxygen species (ROS) production that can be potentially harmful for the cell. The aim of this study was to develop a method that allows stabilizing apoptotic cells for diagnostic and therapeutic applications. By using a cocktail composed of taxol (a microtubule stabilizer), $\mathrm{Zn}^{2+}$ (a caspase inhibitor) and coenzyme $Q_{10}$ (a lipid antioxidant), we were able to stabilize $\mathrm{H} 460$ apoptotic cells in cell cultures for at least $72 \mathrm{~h}$, preventing secondary necrosis. Stabilized apoptotic cells maintain many apoptotic cell characteristics such as the presence of apoptotic microtubules, plasma membrane integrity, low intracellular calcium levels and mitochondrial polarization. Apoptotic cell stabilization may open new avenues in apoptosis detection and therapy.

Cell Death and Disease (2014) 5, e1369; doi:10.1038/cddis.2014.332; published online 14 August 2014

Apoptosis, also known as programmed cell death, is central to homoeostasis and normal development and physiology in multicellular organisms, including humans. ${ }^{1}$ The dysregulation of apoptosis can lead to the destruction of normal tissues in a variety of disorders, including autoimmune and neurodegenerative diseases (increased apoptosis) or cancer (reduced apoptosis). In addition, effective therapy of tumors requires the iatrogenic induction of apoptosis by radiation, chemotherapy or both. In particular, many antineoplasic drugs such as campothecin, a topoisomerase I inhibitor, kill tumor cells by inducing apoptosis.

Apoptosis is thought to be physiologically advantageous because apoptotic cells are removed by phagocytosis before they lose their permeability barrier, thus preventing induction of an inflammatory response to the dying cells and potential harmful secondary effects. However, when massive cell death overwhelms macrophage clearance, as for example in early postchemotherapy or viral infection, ${ }^{2}$ apoptotic cells may progress to secondary necrosis characterized by cell membrane degradation with spillage of intracellular contents to the extracellular milieu. ${ }^{3}$ Similarly, cells undergoing apoptosis in vitro cannot usually be cleared by phagocytes and undergo a late process of secondary necrosis. ${ }^{4}$

In the execution phase of apoptosis, effector caspases cleave vital cellular proteins, leading to the morphological changes that characterize apoptosis. These changes include destruction of the nucleus and other organelles, DNA fragmentation, chromatin condensation, cell shrinkage, cell detachment and membrane blebbing. ${ }^{5}$ In apoptosis, all the degradative processes are isolated from the extracellular space by the plasma membrane that remains impermeable. However, the mechanisms involved in plasma membrane and associated protein protection from the action of caspases are not completely understood. In contrast, necrosis is accompanied by disruption of plasma membrane integrity with the subsequent release of all intracellular compounds to the intercellular space, thus inducing inflammation and more toxic effects to adjacent cells. ${ }^{6,7}$

To allow the dramatic morphological changes that accompany the execution phase, an apoptotic cell undergoes a series of profound cytoskeletal breakdowns/rearrangements. Previous evidence suggests that the actomyosin cytoskeleton plays an essential role in apoptotic cell remodeling during the early events of the execution phase, whereas all other cytoskeleton elements (microtubules and intermediate filaments) are dismantled. ${ }^{8}$ However, during the course of the execution phase and after actininomyosin ring contraction, the actomyosin filaments are also depolymerized by a caspasedependent mechanism. In this situation, the apoptotic cell forms a network of apoptotic microtubules that becomes the main cytoskeleton element of the apoptotic cell. The presence of microtubules in apoptotic cells has previously been reported. $^{9,10}$ Moreover, more recent results indicate that microtubules during apoptosis assist in the dispersal of nuclear and cellular fragments, ${ }^{11,12}$ and may help to preserve the integrity of plasma membrane of the dying cell. ${ }^{13}$

\footnotetext{
${ }^{1}$ Centro Andaluz de Biología del Desarrollo (CABD-CSIC-Universidad Pablo de Olavide), and Centro de Investigación Biomédica en Red Enfermedades Raras, Instituto de Salud Carlos III, Sevilla, Spain; ${ }^{2}$ Laboratorio de Neurociencia Celular y Plasticidad, Universidad Pablo de Olavide, Sevilla, Spain; ${ }^{3}$ Facultad de Odontología, Universidad de Sevilla, Sevilla, Spain and ${ }^{4}$ Sistemas Físicos, Químicos y Naturales-Universidad Pablo de Olavide, Sevilla, Spain

*Corresponding author: JA Sánchez-Alcázar, Centro Andaluz de Biología del Desarrollo (CABD), Consejo Superior de Investigaciones Científicas, Universidad Pablo de Olavide, Carretera de Utrera Km 1, Sevilla 41013, Spain. Tel: +34 95 4978071; Fax: +34 95 4349376; E-mail: jasanalc@upo.es

Abbreviations: $A M N$, apoptotic microtubule network; $\mathrm{CoQ}$, coenzyme $\mathrm{Q}_{10}$; CPT, camptothecin; $\Delta / \mathrm{m}$, mitochondrial membrane potential; FAK, focal adhesion kinase; $\mathrm{GADPH}$, glyceraldehyde-3-phosphate dehydrogenase; LDH, lactic dehydrogenase; PMCA-4, plasma membrane $\mathrm{Ca}^{2+}$ ATPase; PS, phosphatidylserine; ROCK-1, Rho-associated, coiled-coil-containing protein kinase 1

Received 27.3.14; revised 27.6.14; accepted 03.7.14; Edited by R Johnstone
} 
Reactive oxygen species (ROS) are also important mediators of apoptosis. ROS have been shown to play a major role in apoptosis signaling. ${ }^{14-16}$ Electron leak in the presence of oxygen during the process of oxidative phosphorylation make mitochondria the major endogenous source of ROS in the cell. Although mitochondria have been identified as a key player, the mechanism connecting ROS and apoptosis remains unclear. ${ }^{17}$ It has been debated whether increased ROS during apoptosis is a cause or a consequence of impaired mitochondrial function, and whether ROS are a death signal to the mitochondria or are produced as effector molecules by the mitochondria in response to apoptosis signal. ${ }^{18,19}$ Hyperproduction of ROS in execution stages of apoptosis is thought to be caused by the disruption of the mitochondrial respiratory chain after release of cytochrome $c$ into the cytosol. ${ }^{20}$

The main objective of this work was to develop a method for the stabilization of apoptotic cells for proper apoptosis detection or safer potential therapeutic applications. Our results show that apoptotic cells can be stabilized by a cocktail of a microtubule stabilizer (taxol), a caspase inhibitor such $\left(\mathrm{Zn}^{2+}\right)$ and an antioxidant (coenzyme $\left.\mathrm{Q}_{10}(\mathrm{CoQ})\right)$.

\section{Results}

Plasma membrane and the cellular cortex are preserved during apoptosis. To examine the arrangement of microtubules during the execution phase of apoptosis and its relationship with plasma membrane, control and camptothecin (CPT)-induced apoptotic $\mathrm{H} 460$ cells were fixed and stained for $\beta$-tubulin and active caspase-3. Wheat germ agglutinin fluorescent conjugated that selectively recognizes sialic acid and $\mathrm{N}$-acetylglucosaminyl sugar residues was used to reveal plasma membrane (Figures $1 \mathrm{a}$ and b). In control cells, caspase-3 was not activated and microtubules showed their typical interphase radial organization. In apoptotic cells, caspase-3 was activated and the microtubules were reorganized beneath plasma membrane forming the apoptotic microtubule network (AMN). Apoptotic microtubules seemed to work as a physical barrier impeding the access of active caspases to the cellular cortex and plasma membrane (Figure 1b). The cellular cortex that appears as a narrow area between the plasma membrane and the apoptotic microtubules was free of active caspase-3. Altogether, these results suggest that if the cellular cortex is maintained free of the action of caspases by AMN stabilization and/or caspase inhibition, apoptotic cell integrity could be preserved for longer periods of time.

Increased ROS generation during apoptosis. To examine ROS generation during the execution phase of apoptosis, control and apoptotic $\mathrm{H} 460$ cells were stained with MitoSOX, a mitochondrial superoxide fluorescent indicator, and analyzed by fluorescence microscopy and flow cytometry. Figures $1 c$ and d clearly show a notable increase of ROS production in apoptotic cells. These data suggest that antioxidants could be useful for protection and stabilization of apoptotic cells.

Stabilization of apoptotic cells. Previously, we have demonstrated that the execution phase in CPT-induced apoptosis lasts between 50 and $158 \mathrm{~min}$ and is characterized by the presence of the AMN, high mitochondrial polarization and low intracellular calcium levels. ${ }^{21}$ When apoptotic cells undergo secondary necrosis, AMN is disorganized, mitochondrial potential collapses and calcium levels increase, suggesting the loss of plasma membrane integrity (Supplementary Figure 1a).

For the temporal stabilization and longer preservation of cells in apoptosis, apoptotic $\mathrm{H} 460$ cells were treated with $1 \mu \mathrm{M}$ taxol, a microtubule-stabilizing agent to prevent AMN depo-

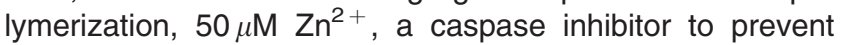
extensive degradation of cellular components and caspasedependent cleavage of cellular cortex and plasma membrane proteins or $50 \mu \mathrm{M} \mathrm{CoQ}$, a lipid-derived antioxidant to protect membranes from oxidative stress or a combination of the three compounds (Supplementary Figure 1b).

Stabilization of apoptotic cells preserves cell attachment and cell content release. First, we obtained a homogeneous synchronized population of $\mathrm{H} 460$ apoptotic cells for subsequent stabilization. To do this, we used the apoptotic cell enrichment assay previously described by our group. ${ }^{13}$ Once we had a homogeneous apoptotic cell population, cells were treated with taxol $(1 \mu \mathrm{M}), \mathrm{Zn}^{2+}(50 \mu \mathrm{M})$ or CoQ $(50 \mu \mathrm{M})$ or with a cocktail composed of the three compounds. After the stabilization treatment, apoptotic cells were incubated for $72 \mathrm{~h}$ and then we examined the number of apoptotic cells that remained attached to the coverslip by light microscopy and the intracellular content release to the medium by measuring (lactate dehydrogenase (LDH) activity by using spectrophotometry (Figures $2 \mathrm{a}-\mathrm{c}$ ). After $72 \mathrm{~h}$ of incubation, most of apoptotic cells without stabilization were detached (Figures $2 \mathrm{a}$ and $\mathrm{b}$ ) from the coverslip and underwent secondary necrosis that was confirmed by the significant increase of $\mathrm{LDH}$ release (Figure $2 \mathrm{c}$ ). On the contrary, stabilization of apoptotic cells by taxol, $\mathrm{Zn}^{2+}$ or $\mathrm{CoQ}$ and more significantly the combined treatment with all the three compounds reduced cell detachment from the coverslip and a decreased $\mathrm{LDH}$ release to the medium, suggesting that plasma membrane integrity was maintained after $72 \mathrm{~h}$ of incubation. These results indicated that an apoptotic-stabilizing cocktail composed of taxol, $\mathrm{Zn}^{2+}$ and $\mathrm{CoQ}$ (apoptotic stabilizer) can be used for apoptotic cell preservation. Stabilized apoptotic cells could be maintained in culture for $96 \mathrm{~h}$ (Supplementary Figures $2 \mathrm{a}$ and b). After $96 \mathrm{~h}$ of incubation, stabilized apoptotic cells underwent secondary necrosis that was characterized by a marked increase of cell detachment and $\mathrm{LDH}$ release. Apoptotic cell stabilization was also confirmed in CPT-induced apoptotic HeLa cells (Supplementary Figures $3 a-c)$.

Stabilization of apoptotic cells prevents plasma membrane permeability. To confirm apoptotic cell stabilization by the combined treatment of taxol, $\mathrm{Zn}^{2+}$ and $\mathrm{CoQ}$ after $72 \mathrm{~h}$ of incubation, we examined plasma membrane permeability in both stabilized apoptotic cells and apoptotic cells without stabilization. Cells were examined using the Dead Red reagent, a red fluorescent nucleic acid stain that only labels permeable cells, thus testing plasma membrane integrity. ${ }^{22}$ These observations were quantified by scoring the proportion 
a
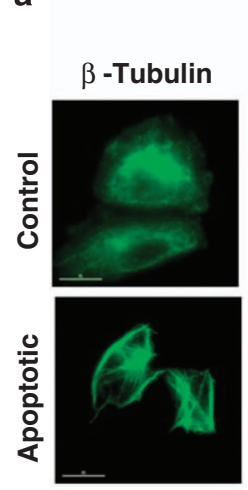

\section{Active} Caspase 3
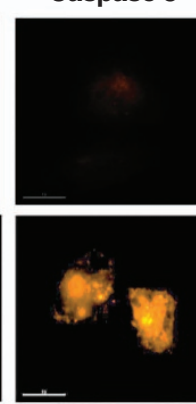
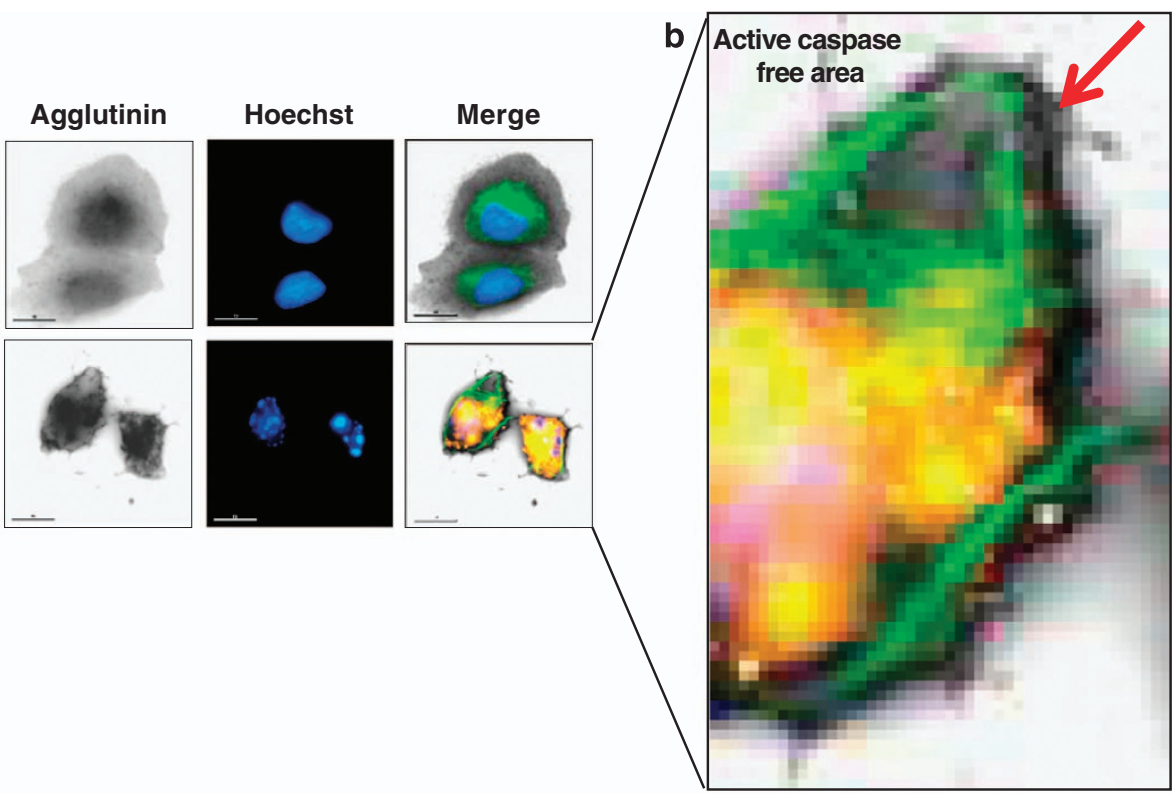

C
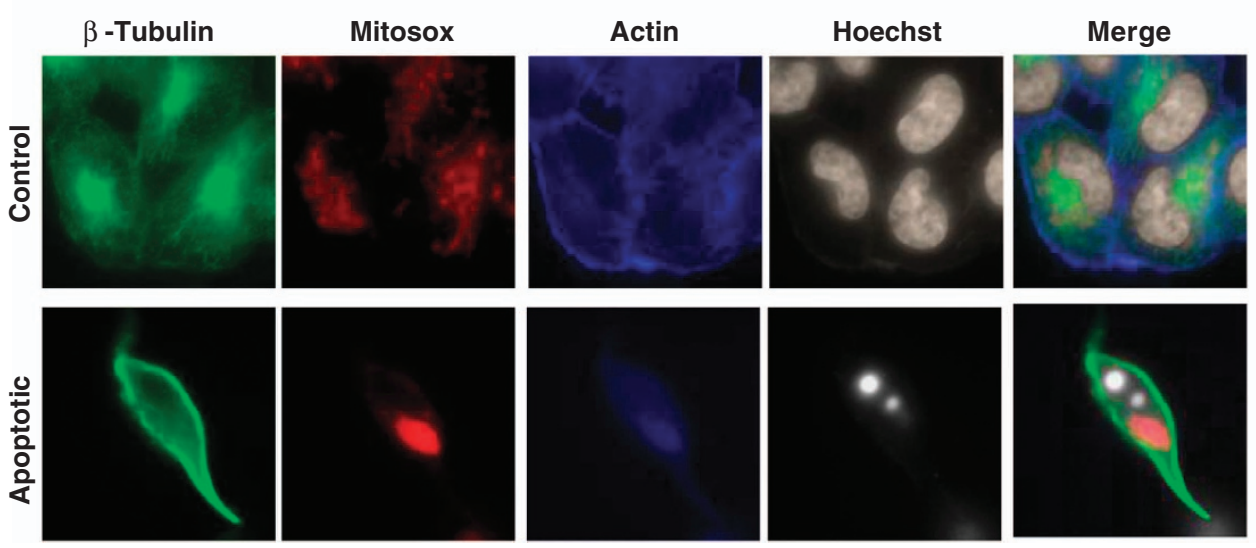

d

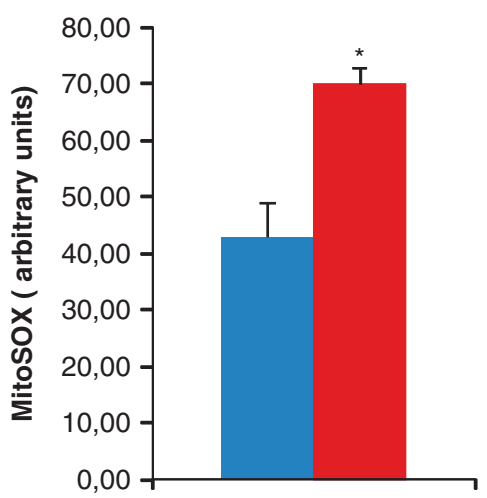

Control

- Apoptotic cells

Figure 1 AMN, caspase activation and ROS production during the execution phase of apoptosis. (a) Fluorescence microscopy of microtubules, plasma membrane and active caspase-3 in $\mathrm{H} 460$ control and apoptotic cells. $\mathrm{H} 460$ cells were grown on glass coverslips and apoptosis was induced as described in the enriched apoptotic assay in the Materials and Methods. Then, cells were fixed and immunostained with anti $\beta$-tubulin (green), anti-active caspase-3. Plasma membrane was revealed by staining with WG agglutinin. Nuclear morphology was revealed by staining with Hoechst $33342(1 \mu \mathrm{g} / \mathrm{ml})$. (b) Magnification of H460 apoptotic cells. (c) Fluorescence microscopy of ROS production in $\mathrm{H} 460$ control and apoptotic cells. $\mathrm{H} 460$ cells were grown on glass coverslips and apoptosis was induced as described in the enriched apoptotic assay in the Materials and Methods. Then, cells were incubated with MitoSOX. After fixation, cells were immunostained with anti $\beta$-tubulin (green). Nuclear morphology was revealed by staining with Hoechst $33342(1 \mu \mathrm{g} / \mathrm{ml})$. Bar $=15 \mu \mathrm{m}$. (d) ROS levels in $\mathrm{H} 460$ control and apoptotic cells were determined by flow cytometry using MitoSOX staining, as described in the Materials and Methods. The y axis of the MitoSOX graph represents the fluorescence intensities of MitoSOX cell samples relative to unstained cells. Data represent means \pm S.D. of three separate experiments. ${ }^{* *} P<0.01$ versus control 


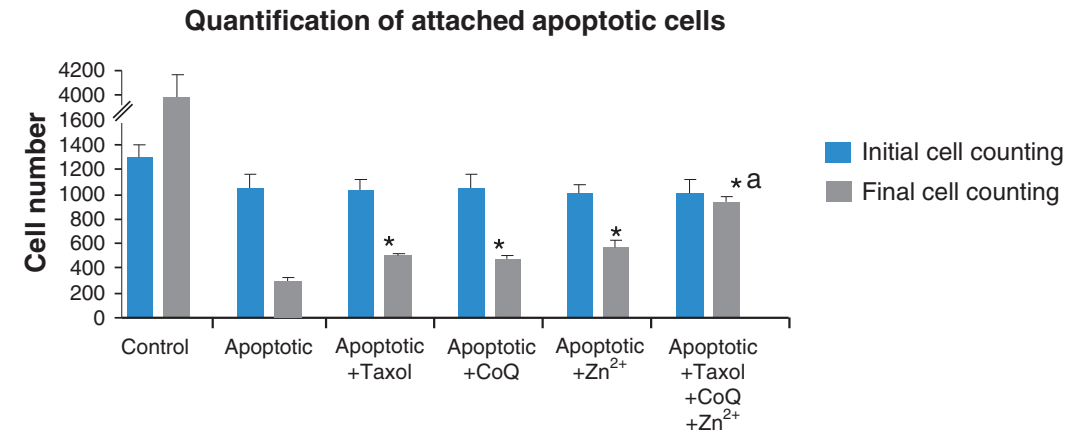

C

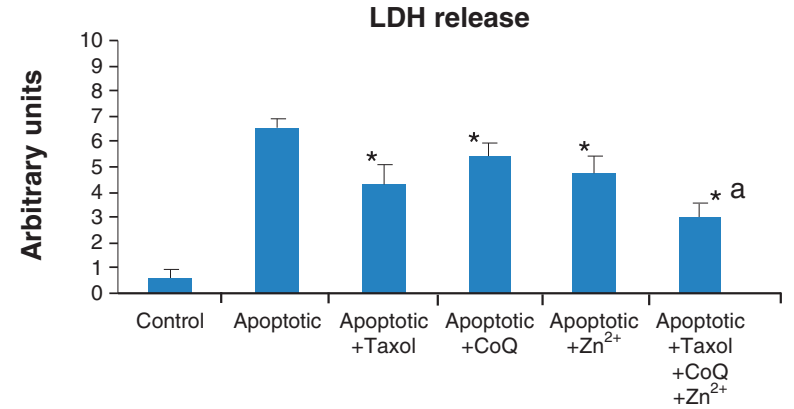

Initial cell counting

Final cell counting

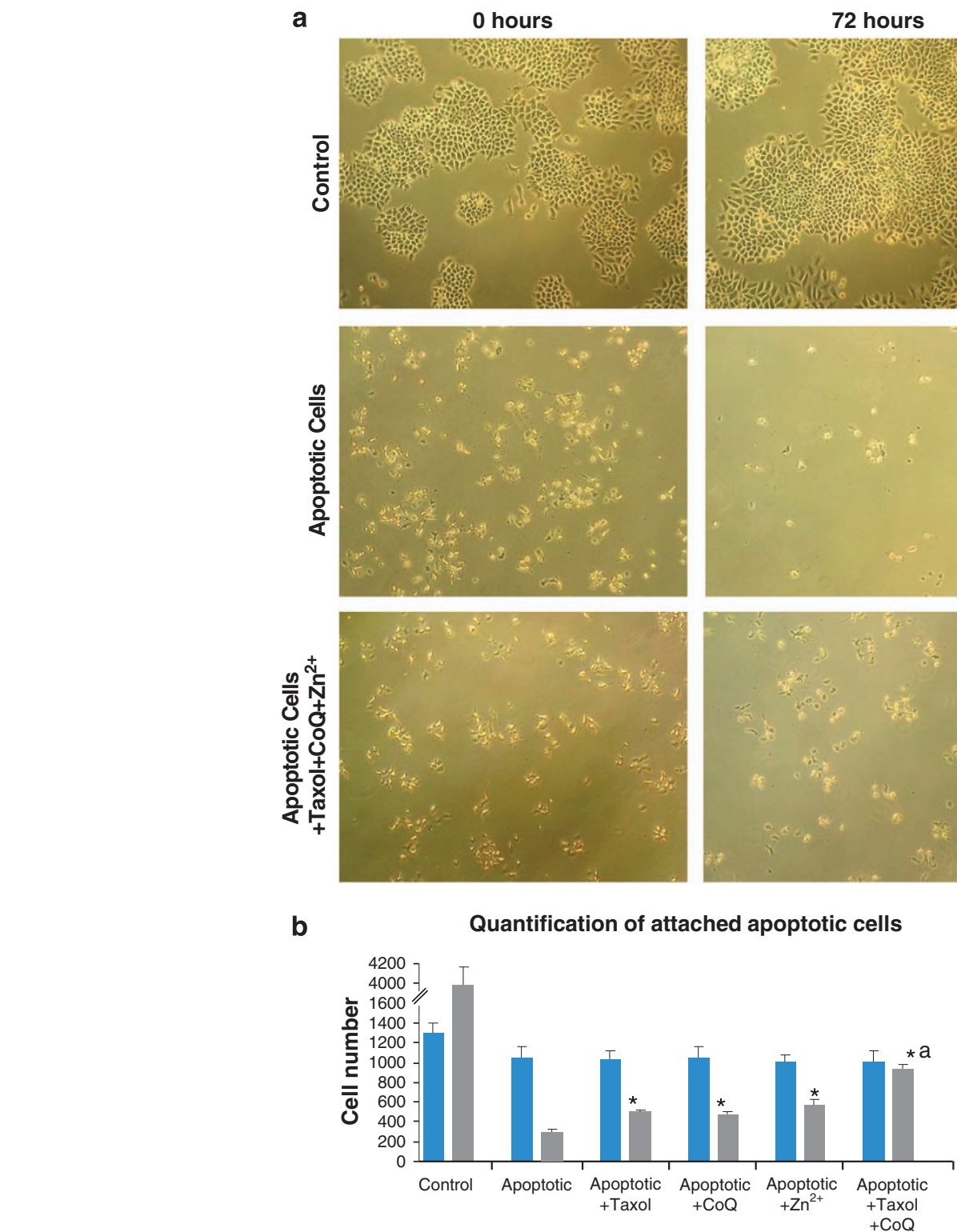
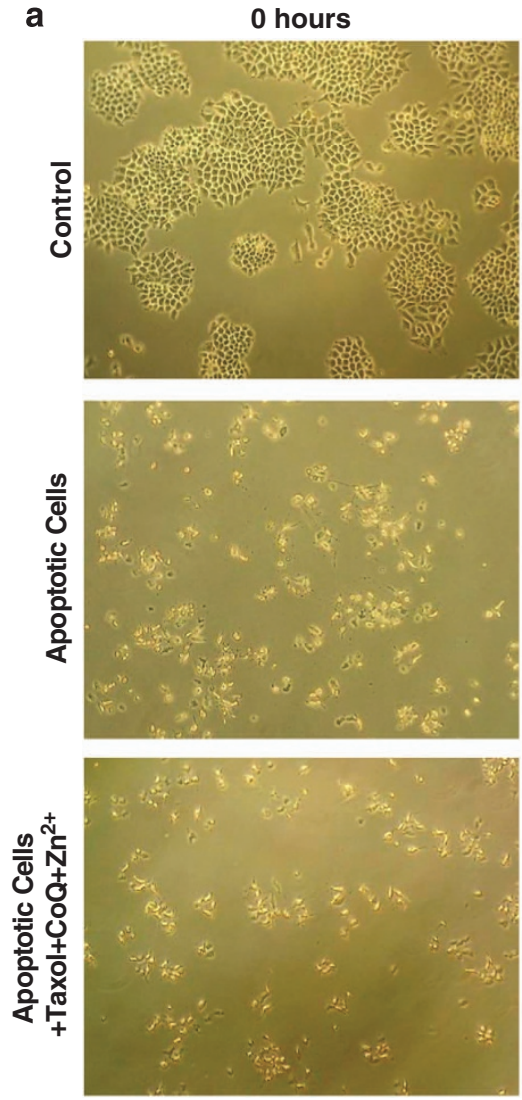

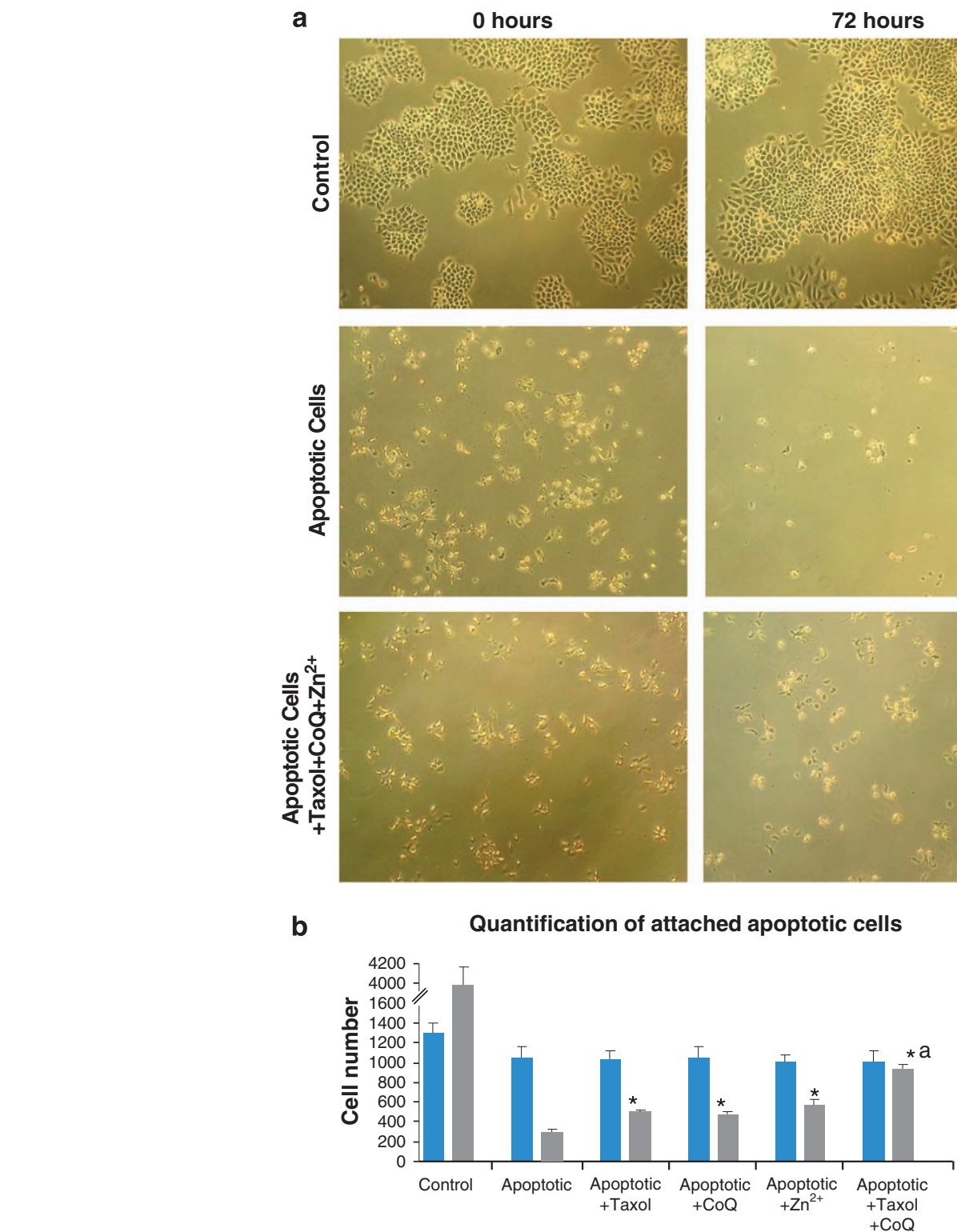

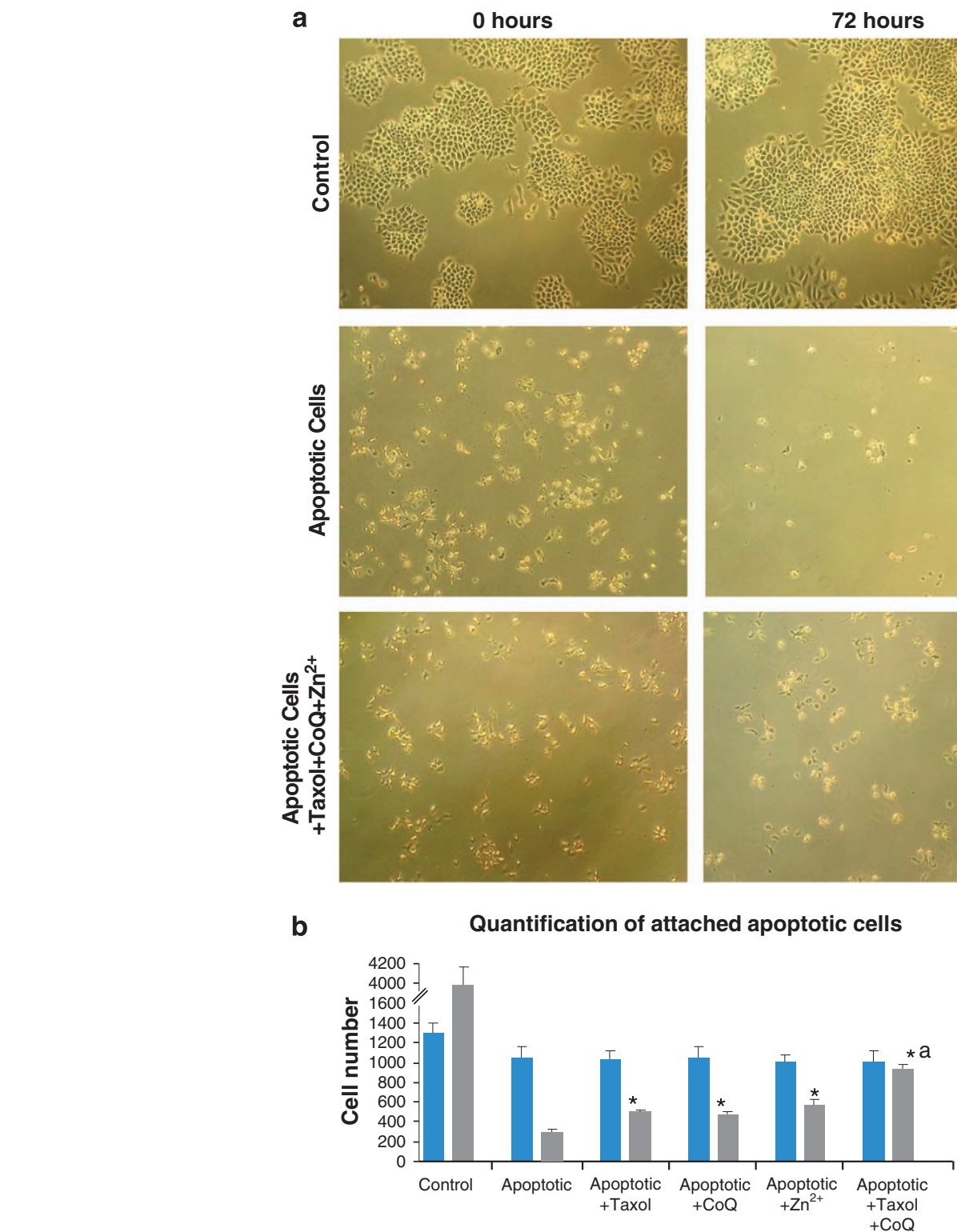
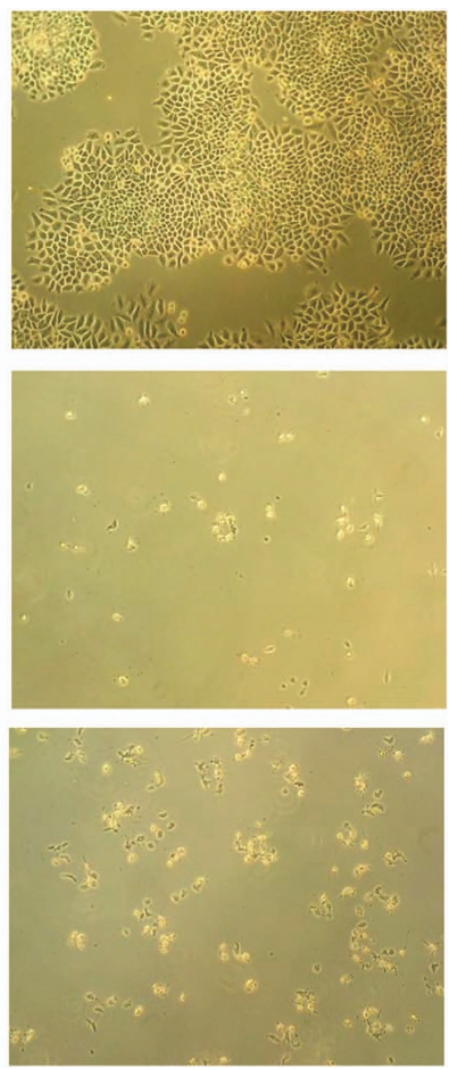

Figure 2 Effect of apoptotic cell stabilization on cell attachment and intracellular content release. Attached cells (a and $\mathbf{b})$ and LDH release (c) in control cells, apoptotic cells without stabilization and apoptotic cells plus $1 \mu \mathrm{M}$ taxol or $50 \mu \mathrm{M} \mathrm{Zn}{ }^{2+}$ or $50 \mu \mathrm{M} \mathrm{CoQ}$ or a combination of all of them after $72 \mathrm{~h}$ of incubation. H460 cells were grown on glass coverslips and apoptosis was induced as described in the enriched apoptotic assay in the Materials and Methods. For apoptotic cell stabilization, apoptotic cells were treated with taxol, $\mathrm{Zn}^{2+}$ and $\mathrm{CoQ}$. Attached cells were scored by microscopy examination. LDH determination in the cultured medium was assessed as described in the Materials and Methods. ${ }^{*} P<0.01$, significant differences with respect to control cells; ${ }^{a} P<0.01$, significant differences with respect to apoptotic cells without stabilization 
of permeable and nonpermeable cells. We found that stabilized apoptotic cells maintained the AMN and were also nonpermeable to the supravital dye (Figures $3 a$ and b). On the contrary, we observed that membrane integrity was impaired in apoptotic cells without stabilization and in control secondary necrotic cells in which AMN was clearly disorganized (Figures $3 a$ and $b$ ). As expected, control cells remained nonpermeable.

Plasma membrane and cell cortex proteins are protected from caspase-mediated cleavage by apoptotic stabilizer. To verify the integrity of cellular cortex and plasma membrane proteins in stabilized apoptotic cells by the combined treatment of taxol, $\mathrm{Zn}^{2+}$ and $\mathrm{CoQ}$ (apoptotic stabilizer) for $72 \mathrm{~h}$, we examined the integrity of well-known cellular cortex and plasma membrane proteins that are common substrates of effector caspases when apoptotic cells undergo secondary necrosis. ${ }^{23}$ Western blotting analysis revealed that initiator caspase- 9 and effector caspases- 3 and -7 were activated and that nuclear (PARP) and cytosolic proteins (Rho-associated, coiled-coil containing protein kinase 1 (ROCK-1)) were cleaved in apoptotic cells with and without stabilization treatment and also in control secondary necrotic cells, thus indicating that active caspases had degraded nuclear and cytosolic components during the execution phase of apoptosis (Figure 3c). However, cellular cortex and transmembrane proteins such as $\alpha$-spectrin, paxilin and plasma membrane $\mathrm{Ca}^{2+}$ ATPase (PMCA-4) were only cleaved when AMN was disorganized in apoptotic cells without stabilization or in control secondary necrotic cells. On the contrary, cellular cortex and plasma membrane proteins were intact in stabilized apoptotic cells that maintain the AMN (Figure 3c). Together, these data indicate that apoptotic cells can be stabilized maintaining the integrity of cellular cortex and plasma membrane proteins.

Apoptotic cell stabilization prevents PMCA-4 cleavage and calcium overload. To confirm plasma membrane protein integrity, we performed immunofluorescence analysis of PMCA-4, a plasma membrane protein involved in calcium extrusion. PMCA-4 integrity was visualized in stabilized apoptotic cells by the combined treatment of taxol, $\mathrm{Zn}^{2+}$ and $\mathrm{CoQ}$ (apoptotic stabilizer) versus nonstabilized apoptotic cells after $72 \mathrm{~h}$ of incubation. Previously, we have demonstrated that PMCA-4 remains intact during the execution phase of apoptosis and is only degraded when cells undergo secondary necrosis. ${ }^{23}$ As shown in Figure $4 a$, stabilized apoptotic cells maintain the AMN and the integrity of PMCA-4. On the contrary, the fluorescent signal of PMCA-4 disappears in apoptotic cells without stabilization and in control secondary necrotic cells in which the AMN was disorganized.

To confirm plasma membrane integrity and PMC-4 functionality, we measured intracellular calcium levels by FLUO-4 staining. Stabilized apoptotic cells showed a moderate increase of FLUO-4 fluorescence with respect to control cells. However, apoptotic cells without stabilization or control secondary necrotic cells showed a notable increase of FLUO-4 fluorescence suggesting increased plasma membrane permeability and calcium overload (Figure 4b).
Mitochondrial membrane potential $(\Delta \psi \mathrm{m})$, ATP levels and ROS production in stabilized apoptotic cells. We have previously demonstrated that $A M N$ during apoptosis depends on energized mitochondria. ${ }^{21}$ Here, we have found that in stabilized apoptotic cells by the combined treatment of taxol, $\mathrm{Zn}^{2+}$ and $\mathrm{CoQ}$ (by the action of the described apoptotic stabilizer), mitochondria maintain a degree of polarization, although this was significantly reduced compared with control cells (Figure 4c). On the contrary, when AMN was disorganized in apoptotic cells without stabilization or in control secondary necrotic cells, a marked mitochondrial depolarization was found (Figure 4c). These results suggest that mitochondrial large depolarization observed during secondary necrosis was significantly prevented in stabilized apoptotic cells. Stabilized apoptotic cells also showed increased ATP levels with respect to secondary necrotic cells, although they were significantly reduced with respect to control cells (Figure 4d). ROS production was also significantly reduced in stabilized apoptotic cells with respect to genuine apoptotic and necrotic cells (Figure 4e).

High phosphatidylserine exposure in stabilized apoptotic cells. Phosphatidylserine (PS) is actively localized on the inner leaflet of the plasma membrane in healthy cells. The asymmetry of its distribution is lost in apoptotic cells. To examine PS exposure in stabilized apoptotic cells by the combined treatment of taxol, $\mathrm{Zn}^{2+}$ and $\mathrm{CoQ}$ (apoptotic stabilizer), we analyzed the binding of Annexin V-FITC to PS by using immunofluorescence and flow cytometry analysis in control, apoptotic cells without stabilization, stabilized apoptotic cells and control secondary necrotic cells. We have found that PS was highly translocated in stabilized apoptotic cells. However, PS translocation was significantly reduced in apoptotic cells without stabilization or in cells suffering secondary necrosis. As expected, control cells did not show PS externalization (Figures $5 a$ and $b$ ).

Stabilized apoptotic cells interact with macrophages. As apoptotic cell stabilization effectively allows high PS externalization, we also tested their binding and uptake by phagocytes. In control, apoptotic cells without stabilization or in control secondary necrotic cells, that is, associated with low PS externalization, the proportion of macrophages interacting with and engulfing apoptotic cells was markedly reduced as compared with stabilized apoptotic cells by the combined treatment of taxol, $\mathrm{Zn}^{2+}$ and $\mathrm{CoQ}$ with high PS externalization (Figures $5 c$ and $d$ ).

Stabilized apoptotic cells maintain plasma membrane potential. To evaluate the effect of apoptotic stabilization on cell plasma membrane potentials, we performed patch-clamp recordings in $\mathrm{H} 460$ control, genuine apoptotic cells before stabilization and stabilized apoptotic cells (stabilized as indicated above by the combined treatment with taxol, $\mathrm{Zn}^{2+}$ and $\mathrm{CoQ}$ ). To acquire information of baseline and to monitor membrane potential $\left(V_{\mathrm{m}}\right)$ at rest, cells were recorded for periods of 20 min using the current-clamp mode of the whole-cell configuration of the patch-clamp technique (Figure $6 \mathrm{a}$ ). $V_{\mathrm{m}}$ was very stable during recordings. H460 control cells showed a $V_{m}$ of $-52 \pm 2$ and $-55 \pm 2 \mathrm{mV}$ at 0 

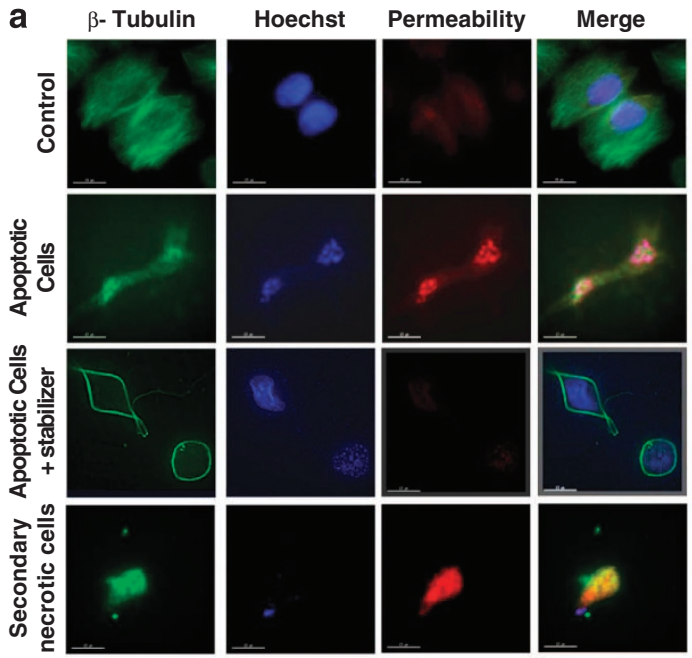

C

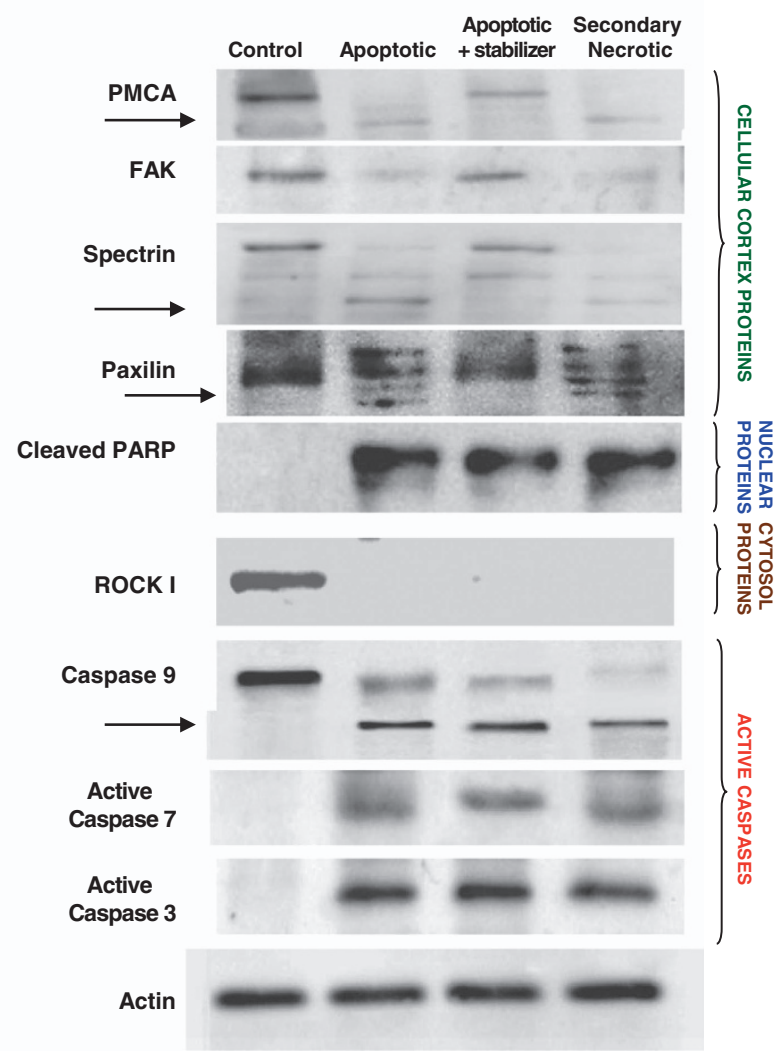

Figure 3 Effect of apoptotic cell stabilization on plasma membrane permeability and protein integrity. (a) Fluorescence microscopy of microtubules and plasma membrane permeability in control cells, apoptotic cells without stabilization, apoptotic cells plus stabilizer and secondary necrotic cells after $72 \mathrm{~h}$ of incubation. H460 cells were grown on glass coverslips and apoptosis was induced as described in the enriched apoptotic assay in the Materials and Methods. For apoptotic cell stabilization, apoptotic cells were treated with $1 \mu \mathrm{M}$ taxol, $50 \mu \mathrm{M} \mathrm{Zn}{ }^{2+}$ and $50 \mu \mathrm{M} \mathrm{CoQ}$ and incubated for $72 \mathrm{~h}$. Control secondary necrotic cells were collected from the floating cells in the medium after treatment with CPT and cytospined on a slide. Before fixation, cells were treated with the Dead Red dye, and then fixed and immunostained with mouse anti- $\beta$-tubulin (green). Nuclear morphology was revealed by staining with Hoechst $33342(1 \mu \mathrm{g} / \mathrm{ml})$. Bar $=15 \mu \mathrm{m}$. (b) Proportion of Dead Red negative (nonpermeable plasma membrane), and Dead Red positive (permeable plasma membrane) in control, apoptotic cells without stabilization, stabilized apoptotic cells and control secondary necrosis H460 cells. More than 100 cells were examined for each experimental condition. ${ }^{\star} P<0.01$, significant differences with respect to control cells; ${ }^{a} P<0.01$, significant differences with respect to apoptotic cells. (c) Western blotting of nuclear (PARP), cytosolic (ROCK-1) and cellular cortex proteins (spectrin, FAK and paxilin) and plasma membrane proteins (PMC-4) in control cells, apoptotic cells without stabilization, stabilized apoptotic cells and control secondary necrotic cells after $72 \mathrm{~h}$ of incubation. Apoptosis in $\mathrm{H} 460 \mathrm{cells}$ was induced as described in the enriched apoptotic assay in the Materials and Methods. Control secondary necrotic cells were collected from the floating cells in the medium after the treatment. For stabilization, apoptotic cells were treated with $1 \mu \mathrm{M}$ taxol, $50 \mu \mathrm{M} \mathrm{Zn^{2+ }}$ and $50 \mu \mathrm{M} \mathrm{CoQ}$. Cell lysates were resolved by SDS-PAGE and protein levels and cleavage fragments (arrows) were determined by western blotting. Equal loading and transfer were shown by repeat probing with anti-actin 
and 20 min after the beginning of the recordings, respectively $(n=11)$. In genuine apoptotic cells before stabilization, the $V_{\mathrm{m}}$ was significantly depolarized compared with control cells $(-16 \pm 3$ and $-17 \pm 2 \mathrm{mV}$ at 0 and $20 \mathrm{~min}, n=6)$. In stabilized apoptotic cells, the $V_{\mathrm{m}}$ was significantly depolarized compared with control cells but very similar to apoptotic cells before stabilization, maintaining a membrane potential of $-17 \pm 3$ and $-14 \pm 3 \mathrm{mV}$ at 0 and $20 \mathrm{~min}$ after the beginning of the recordings, respectively $(n=7$; Figure $6 \mathrm{~b})$. Secondary necrotic cells had a membrane potential close to $0 \mathrm{mV}(-1 \pm 0.5$ and $-2 \pm 0.1 \mathrm{mV}$ at 0 and $20 \mathrm{~min}, n=3)$. To better characterize the electrical properties of the cells, series resistance was monitored and measured during recordings. No changes in series resistance were found during the course of the experiments. Average series resistances were $26 \pm 2,24 \pm 123 \pm 2$ and $25 \pm 1 \mathrm{M} \Omega$ for control, apoptotic cells before stabilization, stabilized apoptotic cells and secondary necrotic cells, respectively, indicating that the apoptotic treatment did not induce any change in this parameter (Figure $6 \mathrm{c}$ ). These results indicate that stabilization of apoptotic cells helps to maintain the values of series resistance, thus contributing to the maintaining of a membrane potential by apoptotic cells.

We next studied the passive membrane properties of control, apoptotic cells before stabilization and stabilized apoptotic cells. For this purpose, a series of test pulses was applied with $10 \mathrm{mV}$ increases in the pulse amplitude per step. According to nonexcitable cell behavior, there was no action potential occurrence at depolarizing potentials (Figure $6 \mathrm{~d}$ ). Furthermore, no occurrence of local potential or other spontaneous activity was observed at very depolarized or hyperpolarized membrane potentials ranging from -100 to $+40 \mathrm{mV}$ (Figure 6e).

It is clear from our results that the induction of apoptosis in $\mathrm{H} 460$ cells by CPT produces changes in the $V_{\mathrm{m}}$ of the cells. The fact that the stabilized apoptotic cells still maintain the same level of $V_{\mathrm{m}}$ than apoptotic cells before stabilization is indicating that the cells are not physiologically dead and that some of the physiological processes of the cell involving the crossing of ions (sodium and potassium ions) and the plasma membrane pump are most probably still working, also indicating that stabilization of apoptotic cells may delay the loss of membrane potential.

Stabilization of apoptotic cells prevents secondary necrosis and allows reliable apoptosis quantification by flow cytometry. It is well known that reliable apoptotic quantification in adherent cell cultures by flow cytometry is difficult and unreliable because of the fact that during the process of cell harvesting and manipulation before and during flow cytometry assays many apoptotic cells undergo secondary necrosis. Therefore, we decided to examine the effect of the stabilizer cocktail in apoptosis quantification by flow cytometry.

With the aim of stabilizing apoptotic cells for reliable diagnostic detection and quantification of apoptosis, we first induced a high population of apoptotic $\mathrm{H} 460$ cells by treatment with $10 \mu \mathrm{M}$ CPT for $48 \mathrm{~h}$. Subsequently, apoptotic cells were incubated in the absence and presence of apoptotic stabilizer (taxol $\left.+\mathrm{Zn}^{2+}+\mathrm{CoQ}\right)$ for 10 min before harvesting. Then, we quantified apoptotic cells and cells in secondary necrosis by flow cytometry by staining with Annexin-FITC and 7-aminoactinomycin (7-AAD) following the standard protocol described in the Materials and Methods section (Supplementary Figures $4 a$ and $b$ ). Results showed that during the process of cell harvesting and manipulation during the flow cytometry assay, many apoptotic cells without stabilization underwent secondary necrosis (42\%). However, the treatment of apoptotic cells with the stabilizer $10 \mathrm{~min}$ before harvesting significantly prevented plasma membrane disruption and secondary necrosis ( $8 \%$ ). These data suggest that stabilization of apoptotic cells may be a very useful tool for reliable apoptosis quantification by flow cytometry assays.

\section{Discussion}

In the present study, we have developed and described an innovative method aimed to the temporal stabilization and preservation of apoptotic cells. This method consists of the combined treatment of apoptotic cells with taxol, $\mathrm{Zn}^{2+}$ and $\mathrm{CoQ}$. This experimental approach guarantees apoptotic cell integrity by preventing plasma membrane permeability and secondary necrosis.

The rationale for using this stabilizing combination was: (1) the use of taxol that, as a microtubule- stabilizing agent, ${ }^{24,25}$ prevents AMN depolymerization and subsequently the access of active caspases to the cellular cortex; (b) the use of $\mathrm{Zn}^{2+}$ that, as a caspase inhibitor, ${ }^{26-29}$ prevents extensive degradation of cellular components and caspase-dependent cleavage of cellular cortex and plasma membrane proteins; and (3) the use of $\mathrm{CoQ}$ that, as an antioxidant, ${ }^{30}$ protects against oxidative membrane damage that is increased in apoptotic cells.

Stabilized apoptotic cells can be considered as dying cells in which the cellular cortex and plasma membrane are maintained intact or alive. In a metaphorical sense, we can consider them as 'living dead' or 'zombie cells'. Stabilized apoptotic retain many of the hallmark characteristics of genuine apoptotic cells such as plasma membrane impermeability, integrity of plasma membrane proteins, low intracellular calcium levels, plasma membrane potential, PS externalization and ability of being phagocytosed.

Interest in apoptosis research has increased considerably recently for a number of reasons including development of therapeutic treatments, cell culture technology development, metabolic engineering of mammalian cells and gene therapy. Furthermore, apoptotic cells play important roles in biomedicine because of their characteristics, and they are being widely used to evaluate the cytotoxic effects of various compounds by quantifying apoptotic cells by flow cytometry. ${ }^{31}$ However, this determination is often affected by the process of cell manipulation (treatments for harvesting, cell centrifugation, cell pipetting and so on), especially in adherent cell cultures required for flow cytometry assays that disrupts plasma membrane permeability and leads apoptotic cells to secondary necrosis. ${ }^{32}$ Therefore, accurate and reliable apoptosis quantifications are particularly difficult in adherent cell cultures. Stabilization of apoptotic cells before cell harvesting allows a more accurate and reliable quantification of the actual number of apoptotic cells or the correct 
determination of biochemical parameters of genuine apoptotic cells such as mitochondrial membrane potential, intracellular calcium concentration, $\mathrm{pH}$, caspase activity and many others, without the interference of plasma membrane disruption and subsequent secondary necrosis.
Moreover, apoptotic cells are currently used for various forms of therapy, primarily with the aim of inducing immunological tolerance in the recipient individual. ${ }^{33}$ The stabilization of apoptotic cells before administration may help to ensure that the inoculated apoptotic cells will retain their a

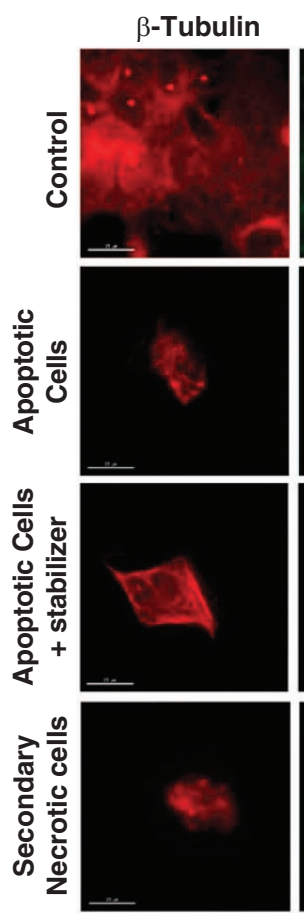

b

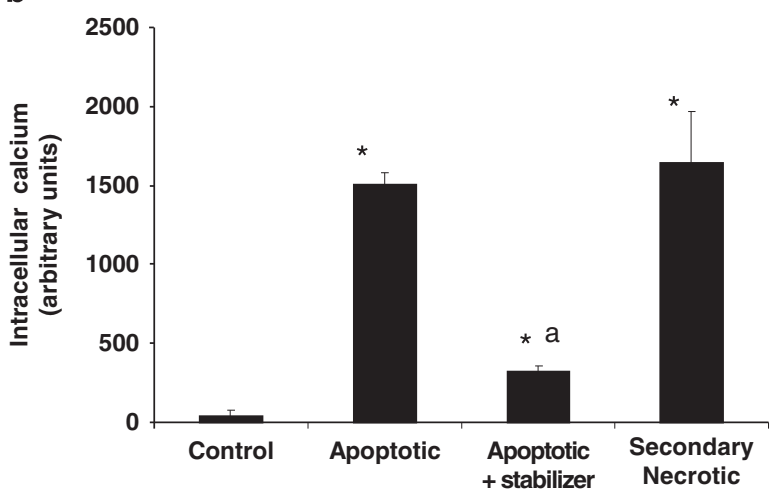

C

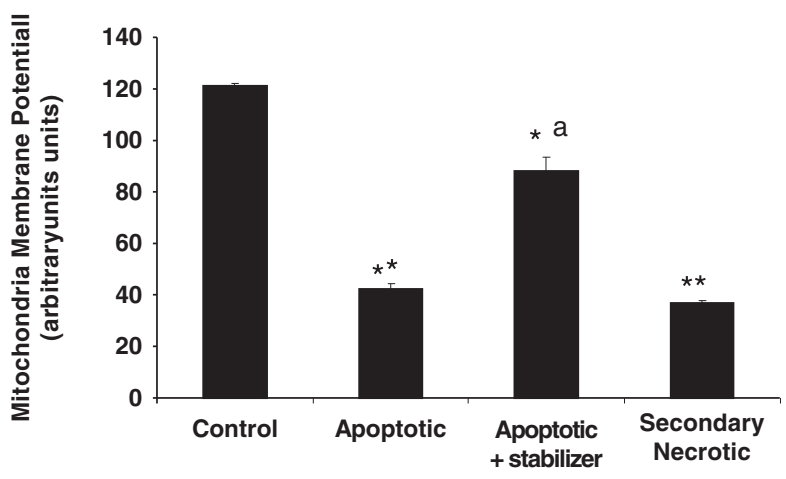

PMCA-4

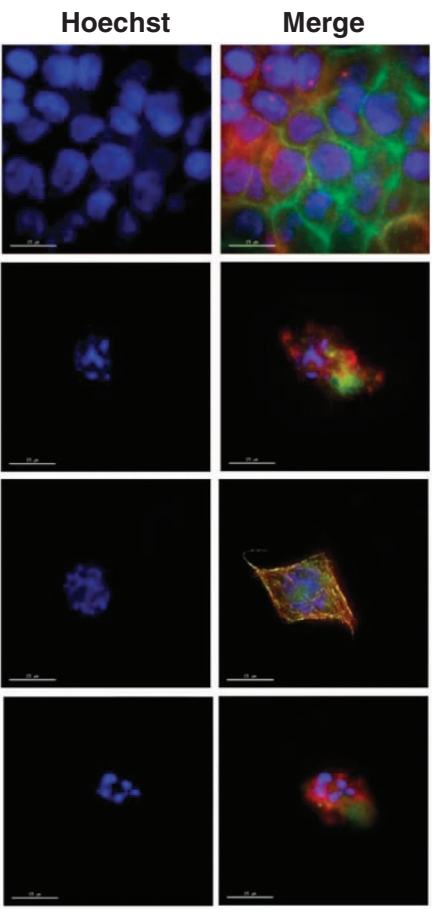

d

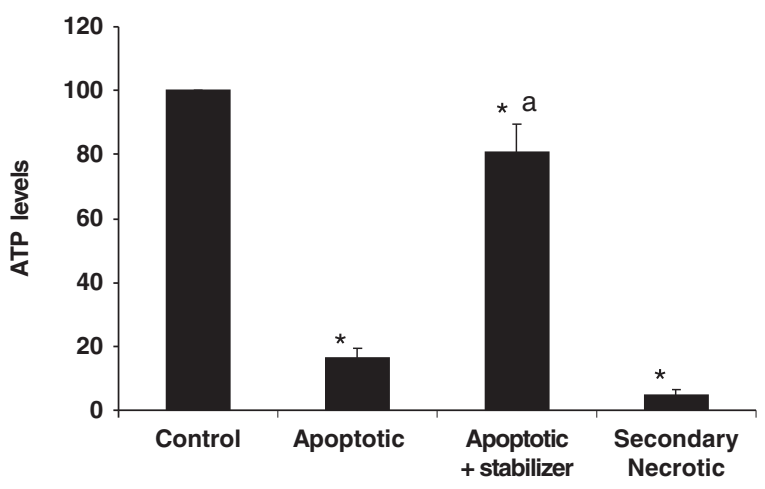

e

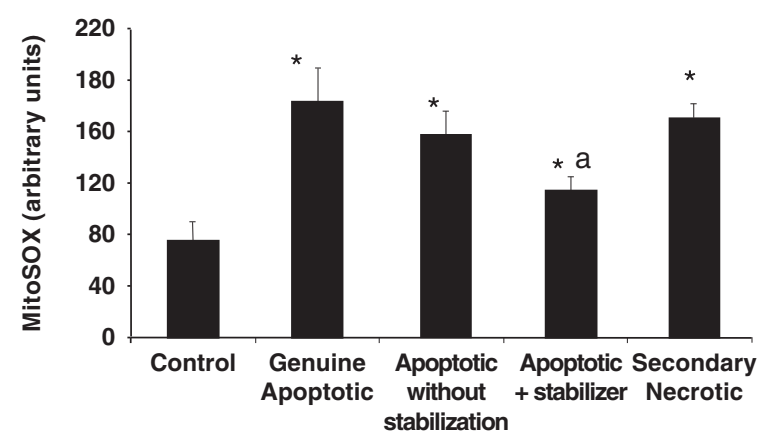


a
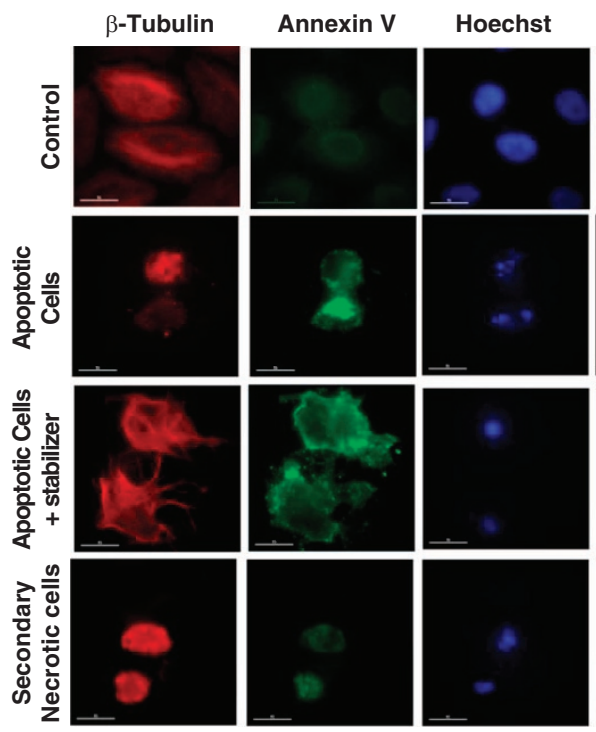

C

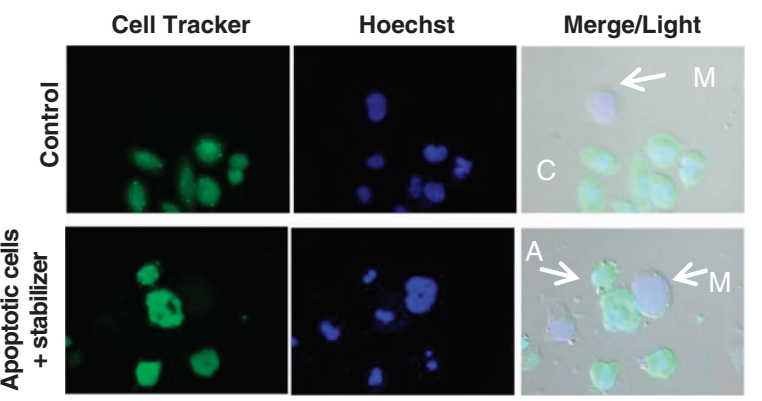

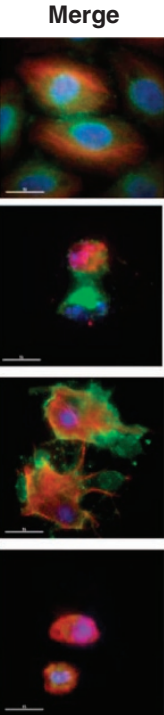

b

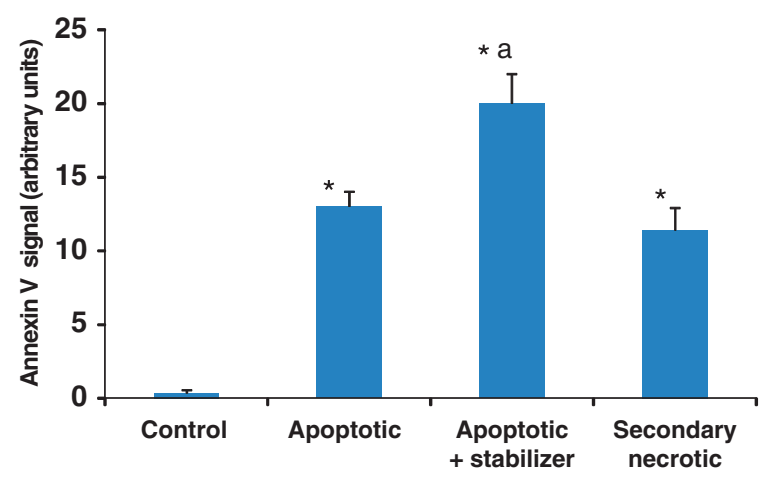

d
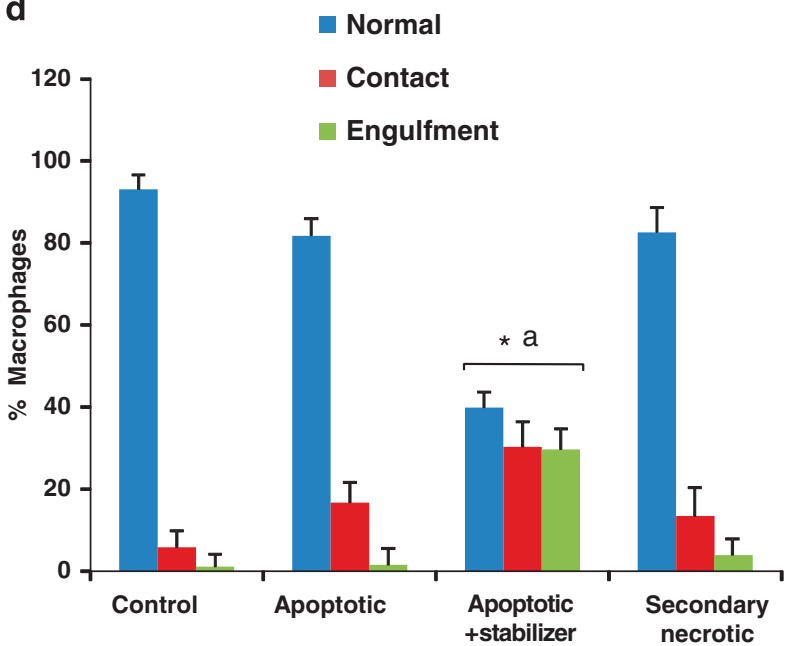

Figure 5 Effect of apoptosis stabilization on PS externalization and interaction with phagocytes. (a) Fluorescence microscopy of microtubules and PS externalization in control cells, apoptotic cells without stabilization, stabilized apoptotic cells and control secondary necrotic cells after $72 \mathrm{~h}$ of incubation. $\mathrm{H} 460$ cells were grown on glass coverslips and apoptosis was induced as described in the enriched apoptotic assay in the Materials and Methods. Secondary necrotic cells were collected from the floating cells in the medium after treatment and cytospined onto a slide. Stabilized apoptotic cells were treated with $1 \mu \mathrm{M}$ taxol, $50 \mu \mathrm{M} \mathrm{Zn^{2+ }}$ and $50 \mu \mathrm{M} \mathrm{CoQ}$. Then, cells were fixed and immunostained with anti $\beta$-tubulin (red), and PS externalization was revealed by staining with Annexin V-FITC. Nuclear morphology was revealed by staining with $\mathrm{Hoechst} 33342(1 \mu \mathrm{g} / \mathrm{ml})$. Bar $=15 \mu \mathrm{m})$. (b) PS externalization was quantified by flow cytometry as described in the Materials and Methods. Data represent the means \pm S.D. of three independent experiments. (c) Wide-field images of CellTracker Green-labeled control and stabilized apoptotic H460 cells (white arrows) interacting with THP-1 macrophages (red arrows). Bars $=15 \mu$ m. (d) Proportion of THP-1 macrophages interacting and engulfing control and stabilized apoptotic $\mathrm{H} 460$ cells. CellTracker Green-labeled $\mathrm{H} 460$ cells were induced into apoptosis by $\mathrm{CPT} /$ cytochalasin as described in the Materials and Methods. Stabilized apoptotic cells were treated with $1 \mu \mathrm{M}$ taxol, $50 \mu \mathrm{M} \mathrm{Zn} n^{2+}$ and $50 \mu \mathrm{M}$ CoQ. Control and stabilized apoptotic cells were then co-incubated with THP-1 macrophages. Nuclear morphology was revealed by staining with Hoechst $33342(1 \mu \mathrm{g} / \mathrm{ml})$. Data represent the means \pm S.D. of three independent experiments. ${ }^{*} P<0.01$, significant differences with respect to control cells; ${ }^{a} P<0.01$, significant differences with respect to apoptotic cells without stabilization

Figure 4 PMCA-4 integrity, mitochondrial membrane potential, ATP and ROS levels after apoptosis stabilization. (a) Fluorescence microscopy of PMCA-4 in control cells, apoptotic cells without stabilization, stabilized apoptotic cells and control secondary necrotic cells after $72 \mathrm{~h}$ of incubation. H460 cells were grown on glass coverslips and apoptosis was induced as is described in the enriched apoptotic assay in the Materials and Methods. Secondary necrotic cells were collected from the floating cells in the medium after treatment and cytospined on a slide. For stabilization, apoptotic cells were treated with $1 \mu \mathrm{M}$ taxol, $50 \mu \mathrm{M} \mathrm{Zn}{ }^{2+}$ and $50 \mu \mathrm{M} \mathrm{CoQ}$. Then, cells were fixed and immunostained with anti PMCA-4 (green) and anti $\beta$-tubulin (red). Nuclear morphology was revealed by staining with $1 \mu \mathrm{g} / \mathrm{ml}$ Hoechst 33342. Bar $=15 \mu \mathrm{m}$. (b) Intracellular calcium levels were measured by flow cytometry using the calcium indicator FLUO-4 $(1 \mu \mathrm{M})$ in control cells, apoptotic cells without stabilization, stabilized apoptotic cells and control secondary necrotic cells after $72 \mathrm{~h}$ of incubation. The y axis of the calcium graph represents the fluorescence intensity of the samples relative to the background intensity. (c) Mitochondrial membrane potential in stabilized apoptotic cells. Mitochondrial membrane potential was measured in control cells, apoptotic cells without stabilization, stabilized apoptotic cells and control secondary necrotic cells after $72 \mathrm{~h}$ of incubation. Apoptosis was induced as described in the enriched apoptotic assay in the Materials and Methods. Secondary necrotic cells were collected from the floating cells in the medium after treatment. Stabilized apoptotic cells were treated with $1 \mu \mathrm{M}$ taxol, $50 \mu \mathrm{M} \mathrm{Zn}{ }^{2+}$ and $50 \mu \mathrm{M} \mathrm{CoQ}$. Mitochondrial membrane potential ( $\Delta \psi / \mathrm{m}$ ) was determined by MitoTracker Red staining and flow cytometry analysis as described in the Materials and Methods. The y axis of the MitoTracker graph represents the fluorescence intensity of the samples relative to the background intensity. (d) ATP levels were measured in control cells, apoptotic cells without stabilization, stabilized apoptotic cells and control secondary necrotic cells after $72 \mathrm{~h}$ of incubation. ATP levels were measured as described in the Materials and Methods. Results were expressed as percentage with respect to ATP levels in control cells. (e) ROS levels were measured in control cells, genuine apoptotic cells, apoptotic cells without stabilization, stabilized apoptotic cells and control secondary necrotic cells after $72 \mathrm{~h}$ of incubation. ROS levels were measured by MitoSOX staining coupled to flow cytometry analysis as described in the Materials and Methods. The y axis of the MitoSOX graph represents the fluorescence intensities of MitoSOX cell samples relative to unstained cells. Data represent the means \pm S.D. of three independent experiments. ${ }^{\star} P<0.01$, significant differences with respect to control cells; ${ }^{a} P<0.01$, significant differences with respect to apoptotic cells without stabilization 
a
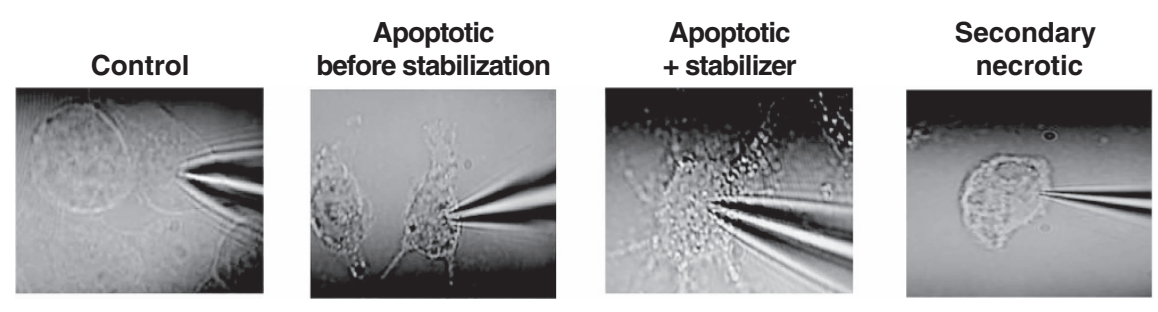

b

C
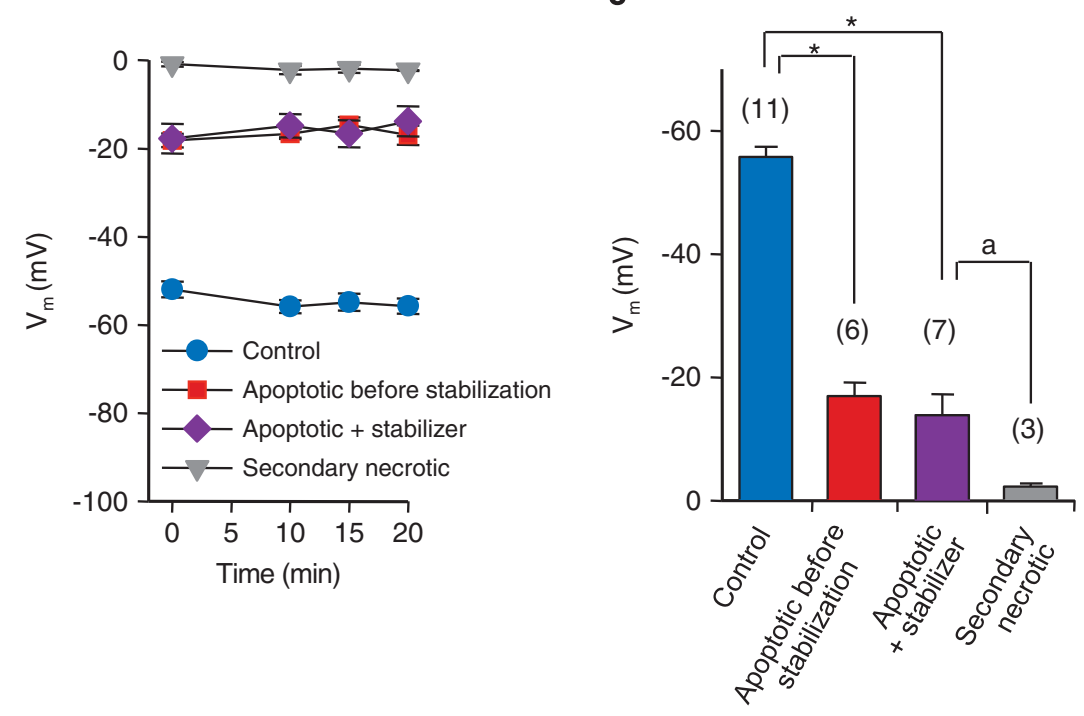

d
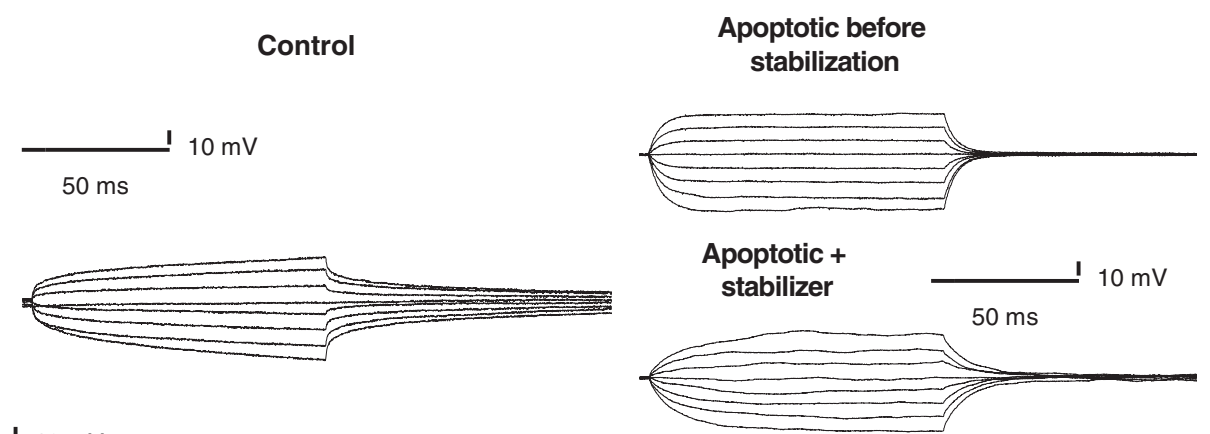

$110 \mathrm{mV}$

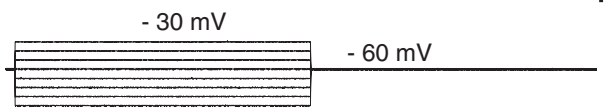

I $10 \mathrm{mV}$

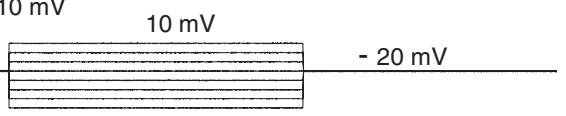

$-100 \mathrm{mV}$

$-60 \mathrm{mV}$

e

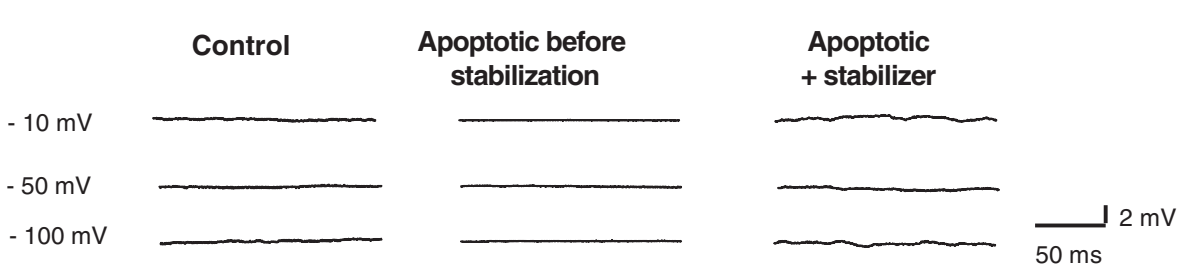

Figure 6 Plasma membrane potential after apoptotic cell stabilization. (a) The pictures show control, genuine apoptotic cells before stabilization and stabilized apoptotic and necrotic cells under recording. (b) Graph shows $V_{m}$ of control (circles), genuine apoptotic cells before stabilization (squares) and stabilized apoptotic (rhombus) and necrotic cells (triangles). Note that stabilized apoptotic cells maintain the same membrane potential as genuine apoptotic cells before stabilization. (c) Quantification of results from (b). ${ }^{\star} P<0.01$. (d) Passive membrane properties of control, genuine apoptotic before stabilization and stabilized apoptotic $\mathrm{H} 460 \mathrm{cells}$. Protocol shows series of test pulses with $10 \mathrm{mV}$ increasing amplitude each step. Representative traces for control (left panel) and apoptotic (genuine before stabilization and stabilized) cells (right panel) are shown. (e) Representative samples showing the lack of activity of control and apoptotic cells (before stabilization and stabilized) in response to depolarizing and hyperpolarizing pulses 
characteristic features until they are phagocytosed by macrophages. The administration of stabilized apoptotic cells can also be used for delivering substances of interest such as therapeutic proteins (for protein replacement therapy) or drugs to recipient macrophages. ${ }^{34}$

There are forms of death that by their nature impair the correct formation of the AMN (e.g., mitochondrial toxics and cold exposure $)^{21}$ and as a result apoptotic cells are not able to maintain plasma membrane integrity and undergo secondary necrosis that may cause serious side effects. Apoptotic cell stabilization may allow the development of therapies for the correct formation and stabilization of AMN, thus promoting a more physiological and controlled type of cell death. Based on the above arguments, there is a need to provide compositions and methods for the stabilization of apoptotic cells.

In summary, we have demonstrated that apoptotic cells can be stabilized for reliable detection and quantification of apoptosis in cultured cells. Stabilization of apoptotic cells may also allow a safer administration of apoptotic cells in clinical applications and opens new avenues in the functional reconstruction of apoptotic cells for longer preservation.

\section{Materials and Methods}

Reagents. CPT was purchased from Alexis Corporation (Nottingham, UK). Cytochalasin, taxol, $\mathrm{ZnSO}_{4}$, Phalloidin-coumarin, trypsin, anti-ROCK-1, anti-actin, coenzyme $Q_{10}$ and anti- $\alpha$-tubulin were purchased from Sigma Chemical Co. (St. Louis, MO, USA). Anti- $\beta$-tubulin antibodies were from Chemicon International (Temecula, CA, USA). Hoechst 33342, FITC-labeled goat anti-mouse and tetramethyl rhodamine goat anti-rabbit antibodies, Dead Red reagent and FLUO-4 were purchased from Molecular Probes (Eugene, OR, USA). Anti-active caspase-3, anti-active caspase-7, anti-caspase-9 and anti-cleaved PARP were obtained from Cell Signaling Technology (Beverly, MA, USA). Anti- focal adhesion kinase (FAK), anti-PMCA-4, anti- $\alpha$-spectrin and anti-paxilin were purchased from Santa Cruz Biotechnology (Santa Cruz, CA, USA). Anti-GADPH was purchased from Calbiochem Merck Millipore (Darmstadt, Germany).

Cell culture. Non-small lung cancer cell line, $\mathrm{H}-460$, was a gift from Dr. PJ Woll (CRC Department of Clinical Oncology, City Hospital, Nottingham, UK). Cells were cultured in RPMI medium supplemented with penicillin, streptomycin and $10 \%$ fetal bovine serum at $37^{\circ} \mathrm{C}$.

Enriched apoptotic assay. Apoptosis was induced to cells by treatment with $10 \mu \mathrm{M}$ CPT, an anticancer drug that inhibits the DNA enzyme topoisomerase I. To increase the proportion of attached apoptotic cells with AMN formation, $\mathrm{H} 460$ cells were treated with CPT + cytochalasin $(2 \mu \mathrm{M})$ for $48 \mathrm{~h}$. To prevent cell cycle effects, cytochalasin was added $24 \mathrm{~h}$ after CPT treatment. Inhibiting actin polymerization, and consequently actin contraction with cytochalasin, CPT induced apoptosis but apoptotic cells maintained the spread state and remained attached to the flask or slide. ${ }^{35}$ Secondary necrotic cells were collected from the floating cells in the medium after CPT treatment.

Apoptotic stabilizer. Apoptotic cell stabilization was performed by treating apoptotic cells with: $1 \mu \mathrm{M}$ taxol, $50 \mu \mathrm{M} \mathrm{Zn}{ }^{2+}\left(\mathrm{ZnSO}_{4}\right)$ or $50 \mu \mathrm{M} \mathrm{CoQ}$, or the combined treatment of the three compounds.

Analysis of apoptosis. Apoptosis was defined by the occurrence of cells with nuclear condensation and fragmentation by Hoechst staining, but retaining plasma membrane integrity (measured by exclusion of the membrane-impermeable dye, Dead Red reagent). Apoptosis was also assessed by caspase activation, cytochrome $c$ release, lack of actin cytoskeleton, presence of apoptotic microtubules and/or cell morphology by phase-contrast microscopy. Primary necrosis was defined as a loss of plasma membrane integrity without signs of nuclear condensation or fragmentation. Secondary necrosis was determined by scoring over time apoptotic cells that became permeable to the Dead Red reagent. Cells were counted for up to $48 \mathrm{~h}$ after CPT/cytochalasin exposure. In each case,
10 random fields and more than 100 cells were counted. To differentiate between genuine apoptotic cells and cells in secondary necrosis, Dead Red reagent was added to the cells $10 \mathrm{~min}$ before fixation.

Immunofluorescence studies. $\mathrm{H} 460$ cells were grown on $1 \mathrm{~mm}$ (Thermo Scientific Gold Seal, Waltham, MA, USA) glass coverslips for $24-48 \mathrm{~h}$ in RPMI containing $10 \%$ FBS. After treatments, cells were rinsed once with PBS, fixed in $3.8 \%$ paraformaldehyde for $5 \mathrm{~min}$ at room temperature and permeabilized in $0.1 \%$ saponin for $5 \mathrm{~min}$. For immunostaining, glass coverslips were incubated with primary antibodies diluted $1: 100$ in PBS for $1-2 \mathrm{~h}$ at $37^{\circ} \mathrm{C}$ in a humidified chamber. Excess antibody binding was removed by washing the coverslips with PBS (three times, $5 \mathrm{~min}$ ). The secondary antibody, a FITC-labeled goat antimouse antibody or a tetramethyl rhodamine goat anti-rabbit (Molecular Probes), diluted 1:100 in PBS, were added and incubated for $1 \mathrm{~h}$ at $37^{\circ} \mathrm{C}$. Coverslips were then rinsed with PBS for 3 min, incubated for 1 min with PBS containing Hoechst $33342(1 \mu \mathrm{g} / \mathrm{ml})$ and washed with PBS (three 5-min washes). Finally, the coverslips were mounted onto microscope slides using Vectashield Mounting Medium (Vector Laboratories, Burlingame, CA, USA) and analyzed using an upright fluorescence microscope (Leica DMRE, Leica Microsystems $\mathrm{GmbH}$, Wetzlar, Germany). Deconvolution studies and 3D projections were performed using a DeltaVision system (Applied Precision, Issaquah, WA, USA) with an Olympus IX-71 microscope with $\times 100$ objective/1.35 NA and $\times 60$ objective/1.40 NA (Olympus, Tokyo, Japan) and filters set for DAPI, fluorescein isothiocyanate, and rhodamine provided by Applied Precision. Acquired z planes were separated by $0.3 \mu \mathrm{m}$, and an average of 50 planes was taken for each nucleus. The $3 \mathrm{D}$ stacks were deconvolved using the Softworx software algorithm (conservative ratio method, 10 iterations; Applied Precision).

Western blotting analysis. Whole cellular lysates were prepared in a buffer, with gentle shaking, composed of $0.9 \% \mathrm{NaCl}, 20 \mathrm{mM}$ Tris- $\mathrm{HCl}, \mathrm{pH} 7.6$, $0.1 \%$ Triton X-100, $1 \mathrm{mM}$ phenylmethylsulfonylfluoride and $0.01 \%$ leupeptine. Electrophoresis was carried out in a $10-15 \%$ acrylamide SDS-PAGE. Proteins were transferred to Immobilon membranes (Amersham Pharmacia, Buckinghamshire, UK). Proteins were electrophorezed, transferred to nitrocellulose membranes and, after blocking overnight at $4^{\circ} \mathrm{C}$, incubated with the respective antibody solution at 1:1000 dilutions. Then, membranes were probed with their respective secondary antibody $(1: 2500)$. Immunolabeled proteins were detected by using a chemioluminiscence method (Bio-Rad, Hercules, CA, USA). Protein was determined by the Bradford method. ${ }^{36}$

Cell content release: LDH determination. Plasma membrane integrity and cell content release was monitored by measuring LDH activity into the incubation medium. This was done using a commercial kit (CytoTox 96 NonRadioactive Cytotoxicity Assay from Promega (Madison, WI, USA).

Determination of intracellular calcium levels by flow cytometry. $\mathrm{H} 460$ cells were incubated for $60 \mathrm{~min}$ at $37^{\circ} \mathrm{C}$ in medium supplemented with $1 \mu \mathrm{M}$ FLUO-4, AM. Cells were then washed three times with RPMI medium, fixed with $3.8 \%$ paraformaldehyde and analyzed by flow cytometry using an EPICS Elite flow cytometer (Beckman-Coulter, Hialeah, FL, USA).

Measurement of $\Delta \psi \mathrm{m}$ by flow cytometry. $\mathrm{H} 460$ cells were incubated for $60 \mathrm{~min}$ at $37^{\circ} \mathrm{C}$ in medium supplemented with $1 \mu \mathrm{m}$ Mitotracker Red (Molecular Probes). Cells were then washed three times with RPMI medium, fixed with $3.8 \%$ paraformaldehyde and analyzed by flow cytometry.

ATP determination. ATP levels were determined by using a luciferasebased assay according to the directions of Molecular Probes, using a Tuner Designs Luminometer TD 20/20 (Sunnyvale, CA, USA).

Measurement of intracellular generation of ROS. Mitochondrial ROS generation in fibroblasts was assessed by MitoSOX, a red mitochondrial superoxide indicator. Once in the mitochondria, MitoSOX red reagent is oxidized by superoxide and exhibits red fluorescence. Approximately $1 \times 10^{6}$ cells were incubated with $1 \mu \mathrm{M}$ MitoSOX for $30 \mathrm{~min}$ at $37^{\circ} \mathrm{C}$, washed twice with PBS, resuspended in $500 \mu \mathrm{l}$ of PBS and analyzed by flow cytometry (excitation at $510 \mathrm{~nm}$ and fluorescence detection at $580 \mathrm{~nm}$ ). Specificity of MitoSOX for superoxide has been shown by the manufacturer, and its mitochondrial localization was tested by co-staining with MitoTracker Green (data not shown). 
Electrophysiological recordings. Somatic whole-cell patch-clamp recordings were made from healthy (control), nonstabilized and stabilized apoptotic $\mathrm{H} 460$ cells and necrotic cells. These cells were visually identified by IR-DIC (infrared-differential interference contrast) microscopy using a $40 \times$ water immersion objective. Cells were perfused at a flow rate of $3.5 \mathrm{ml} / \mathrm{min}$ with a solution containing (in $\mathrm{mM}$ ): $\mathrm{NaCl} 126 ; \mathrm{KCl} 3 ; \mathrm{NaH}_{2} \mathrm{PO}_{4} 1.25 ; \mathrm{MgSO}_{4} 2 ; \mathrm{CaCl}_{2} 2$; $\mathrm{NaHCO}_{3} 26$; glucose 10, $\mathrm{pH} 7.2-7.4$; bubbled with carbogen gas $\left(95 \% \mathrm{O}_{2} / 5 \%\right.$ $\mathrm{CO}_{2}$ ). All experiments were performed at $37^{\circ} \mathrm{C}$. Patch electrodes were made from borosilicate glass, and had a resistance of $4-7 \mathrm{M} \Omega$ when filled with (in $\mathrm{mM}$ ): potassium gluconate 110; HEPES 40; $\mathrm{NaCl} 4$; ATP-Mg 4; GTP 0.3 (pH 7.2, $290 \mathrm{mOsm}$ ). Cells were voltage clamped, using a Multiclamp 700B amplifier (Molecular Devices, Foster City, CA, USA). Access resistance was regularly monitored during recordings, and cells were rejected if it changed $>15 \%$ during the experiment. Data were filtered at $2 \mathrm{kHz}$, digitized at $10 \mathrm{kHz}$ and stored on a computer using pClamp software (Molecular Devices). Membrane potentials $\left(V_{\mathrm{m}}\right)$ of the cells were recorded by using the current-clamp mode of the amplifier. $V_{m}$ were measured continuously during the experiments. Average values indicated in the text correspond to $V_{\mathrm{m}}$ at 5 and $15 \mathrm{~min}$ after the beginning of the recordings. Potentials were obtained by applying a series of test pulses from a holding potential of $-60 \mathrm{mV}$ (control healthy cells) and $-20 \mathrm{mV}$ (apoptotic cells) with $10 \mathrm{mV}$ increases in pulse amplitude per step.

Determination of PS externalization. PS translocation from the inner to the outer leaflet of the plasma membrane is one of the earliest apoptotic features. We used the PS-binding protein Annexin V conjugated with FITC to identify PS exposure in $\mathrm{H} 460$ cells. The binding of annexin V to cell surface PS was detected with a commercial Annexin Apoptosis Kit (Santa Cruz Biotechnology) according to the manufacturer's instructions. To distinguish cells that had lost membrane integrity, propidium iodide (PI) was added to a final concentration of $10 \mu \mathrm{g} / \mathrm{ml}$ immediately before analysis. Apoptotic cells were identified either by fluorescence microscopy or by flow cytometry. Hoechst $33342(1 \mu \mathrm{g} / \mathrm{ml})$ staining was used to reveal nuclear condensation/fragmentation.

Phagocytosis assays. CellTracker-labeled H460 cells (Molecular Probes) that adhered to glass coverslips were induced into apoptosis by CPT/cytochalasin treatment and then were incubated for $1 \mathrm{~h}$ in the absence or presence of colchicine or colchicine plus z-VAD. Then, cells were washed and co-incubated with PMA-differentiated THP-1 macrophages (150000 cells/well). Floating apoptotic cells representing secondary necrotic cells were cytospined onto coverslips and also co-incubated with PMA-differentiated THP-1 macrophages. After $8 \mathrm{~h}$ of co-incubation at $37^{\circ} \mathrm{C}$, coverslips were washed extensively in PBS and cells were fixed in $3.8 \%$ paraformaldehyde. The number of THP-1 macrophages interacting (bound and engulfed) and engulfing cell fragments was calculated in 10 random fields in triplicate by fluorescence and phase-contrast microscopy.

Apoptosis flow cytometry assay. We followed a standard protocol supplied by Santa Cruz Biotechnology (Annexin V-FITC: sc-4252 FITC). Control and apoptotic $\mathrm{H} 460$ cells were trypsinized and transferred to a $15 \mathrm{ml}$ conical tube. Cells were pelleted by low speed centrifugation at 1500 r.p.m. for $5 \mathrm{~min}$. Gently wash in medium containing serum. Next, cells were washed once with PBS and resuspended in $1 \times$ Assay Buffer at a concentration of $1 \times 10^{6} \mathrm{cell} / \mathrm{s} / \mathrm{ml}$. Then, $100 \mu \mathrm{l}$ aliquot of cells $\left(1 \times 10^{5}\right.$ cells) was transferred to a $5-\mathrm{ml}$ culture tube and $1 \mu \mathrm{g} / \mathrm{ml}$ of Annexin V-FITC and $1 \mu \mathrm{g} / \mathrm{ml}$ 7-ADD was added. Recommended negative controls for flow cytometry include: (1) no Annexin V-FITC and no 7-ADD; (2) Annexin V-FITC alone and (3) 7-ADD alone. Subsequently, samples were gently vortexed and incubated for $15 \mathrm{~min}$ at room temperature in the dark. Immediately, samples were analyzed by flow cytometry.

Statistical analysis. All results are expressed as means \pm S.D. unless stated otherwise. Two-tailed Student's t-tests (paired and unpaired, according to samples) or ANOVA variance analysis were used as appropriate for statistical analysis. Only $P$-values of $<0.05$ were considered as statistically significant.

\section{Conflict of Interest}

The authors declare no conflict of interest.
Acknowledgements. This work was supported by FIS PI10/00543 grant, Ministerio de Sanidad, Spain, and Fondo Europeo de Desarrollo Regional (FEDERUnión Europea), SAS 111242 grant, Servicio Andaluz de Salud-Junta de Andalucía, Proyecto de Investigación de Excelencia de la Junta de Andalucía CTS-5725, BFU2012-38208 and by AEPMI (Asociación de Enfermos de Patología Mitocondrial).

1. Kerr JF, Wyllie AH, Currie AR. Apoptosis: a basic biological phenomenon with wide-ranging implications in tissue kinetics. Br J Cancer 1972; 26: 239-257.

2. Wyllie AH. The biology of cell death in tumours. Anticancer Res 1985; 5: 131-136.

3. Wyllie AH. Apoptosis: an overview. Br Med Bull 1997; 53: 451-465.

4. Afford S, Randhawa S. Apoptosis. Mol Pathol 2000; 53: 55-63.

5. Fischer U, Janicke RU, Schulze-Osthoff K. Many cuts to ruin: a comprehensive update of caspase substrates. Cell Death Differ 2003; 10: 76-100.

6. Savill J, Dransfield I, Gregory C, Haslett C. A blast from the past: clearance of apoptotic cells regulates immune responses. Nat Rev Immunol 2002; 2: 965-975.

7. Zong WX, Thompson CB. Necrotic death as a cell fate. Genes Dev 2006; 20: 1-15.

8. Mills JC, Stone NL, Pittman RN. Extranuclear apoptosis. The role of the cytoplasm in the execution phase. J Cell Biol 1999; 146: 703-708.

9. Pittman S, Geyp M, Fraser M, Ellem K, Peaston A, Ireland C. Multiple centrosomal microtubule organising centres and increased microtubule stability are early features of VP-16-induced apoptosis in CCRF-CEM cells. Leuk Res 1997; 21: 491-499.

10. Pittman SM, Strickland D, Ireland CM. Polymerization of tubulin in apoptotic cells is not cell cycle dependent. Exp Cell Res 1994; 215: 263-272.

11. Moss DK, Betin VM, Malesinski SD, Lane JD. A novel role for microtubules in apoptotic chromatin dynamics and cellular fragmentation. J Cell Sci 2006; 119(Pt 11): 2362-2374.

12. Moss DK, Lane JD. Microtubules: forgotten players in the apoptotic execution phase. Trends Cell Biol 2006; 16: 330-338.

13. Sanchez-Alcazar JA, Rodriguez-Hernandez A, Cordero MD, Fernandez-Ayala DJ, Brea-Calvo G, Garcia $\mathrm{K}$ et al. The apoptotic microtubule network preserves plasma membrane integrity during the execution phase of apoptosis. Apoptosis 2007; 12: $1195-1208$.

14. Iverson SL, Orrenius S. The cardiolipin-cytochrome $\mathrm{c}$ interaction and the mitochondrial regulation of apoptosis. Arch Biochem Biophys 2004; 423: 37-46.

15. Nishimura G, Proske RJ, Doyama H, Higuchi M. Regulation of apoptosis by respiration: cytochrome $c$ release by respiratory substrates. FEBS Lett 2001; 505: 399-404.

16. Simon HU, Haj-Yehia A, Levi-Schaffer F. Role of reactive oxygen species (ROS) in apoptosis induction. Apoptosis 2000; 5: 415-418.

17. Petrosillo G, Ruggiero FM, Paradies $G$. Role of reactive oxygen species and cardiolipin in the release of cytochrome c from mitochondria. FASEB J 2003; 17: 2202-2208.

18. Hampton MB, Orrenius $S$. Redox regulation of apoptotic cell death in the immune system. Toxicol Lett 1998; 102-103: 355-358.

19. Slater AF, Stefan C, Nobel I, van den Dobbelsteen DJ, Orrenius S. Intracellular redox changes during apoptosis. Cell Death Differ 1996; 3: 57-62.

20. Cai J, Jones DP. Superoxide in apoptosis. Mitochondrial generation triggered by cytochrome c loss. J Biol Chem 1998; 273: 11401-11404.

21. Oropesa M, de la Mata M, Maraver JG, Cordero MD, Cotan D, Rodriguez-Hernandez A et al. Apoptotic microtubule network organization and maintenance depend on high cellular ATP levels and energized mitochondria. Apoptosis 2011; 16: 404-424.

22. Sanchez-Alcazar JA, Khodjakov A, Schneider E. Anticancer drugs induce increased mitochondrial cytochrome $c$ expression that precedes cell death. Cancer Res 2001; 61: 1038-1044.

23. Oropesa-Avila M, Fernandez-Vega A, de la Mata M, Maraver JG, Cordero MD, Cotan D et al. Apoptotic microtubules delimit an active caspase free area in the cellular cortex during the execution phase of apoptosis. Cell Death Dis 2013; 4: e527.

24. Schiff PB, Fant J, Horwitz SB. Promotion of microtubule assembly in vitro by taxol. Nature 1979; 277: 665-667

25. Schiff PB, Horwitz SB. Taxol stabilizes microtubules in mouse fibroblast cells. Proc Natl Acad Sci USA 1980; 77: 1561-1565.

26. Huber KL, Hardy JA. Mechanism of zinc-mediated inhibition of caspase-9. Protein Sci 2012; 21: 1056-1065.

27. Perry DK, Smyth MJ, Stennicke HR, Salvesen GS, Duriez P, Poirier GG et al. Zinc is a potent inhibitor of the apoptotic protease, caspase-3. A novel target for zinc in the inhibition of apoptosis. J Biol Chem 1997; 272: 18530-18533.

28. Smith AF, Longpre J, Loo G. Inhibition by zinc of deoxycholate-induced apoptosis in HCT-116 cells. J Cell Biochem 2012; 113: 650-657.

29. Stennicke HR, Salvesen GS. Biochemical characteristics of caspases-3, $-6,-7$, and -8 . J Biol Chem 1997; 272: 25719-25723.

30. Bentinger M, Brismar K, Dallner G. The antioxidant role of coenzyme Q. Mitochondrion 2007; 7(Suppl): S41-S50.

31. Darzynkiewicz Z, Bruno S, Del Bino G, Gorczyca W, Hotz MA, Lassota P et al. Features of apoptotic cells measured by flow cytometry. Cytometry 1992; 13: 795-808.

32. van Engeland M, Ramaekers FC, Schutte B, Reutelingsperger CP. A novel assay to measure loss of plasma membrane asymmetry during apoptosis of adherent cells in culture. Cytometry 1996; 24: 131-139. 
33. Saas P, Kaminski S, Perruche S. Prospects of apoptotic cell-based therapies for transplantation and inflammatory diseases. Immunotherapy 2013; 5 1055-1073.

34. Perez B, Paquette N, Paidassi H, Zhai B, White K, Skvirsky R et al. Apoptotic cells can deliver chemotherapeutics to engulfing macrophages and suppress inflammatory cytokine production. J Biol Chem 2012; 287: 16029-16036.

35. Huot J, Houle F, Rousseau S, Deschesnes RG, Shah GM, Landry J. SAPK2 p38-dependent F-actin reorganization regulates early membrane blebbing during stress-induced apoptosis. J Cell Biol 1998; 143: 1361-1373.

36. Bradford MM. A rapid and sensitive method for the quantitation of microgram quantities of protein utilizing the principle of protein-dye binding. Anal Biochem 1976; 72: $248-254$
Cell Death and Disease is an open-access journal published by Nature Publishing Group. This work is licensed under a Creative Commons Attribution-NonCommercialNoDerivs 3.0 Unported License. The images or other third party material in this article are included in the article's Creative Commons license, unless indicated otherwise in the credit line; if the material is not included under the Creative Commons license, users will need to obtain permission from the license holder to reproduce the material. To view a copy of this license, visit http://creativecommons.org/licenses/ by-nc-nd/3.0/

Supplementary Information accompanies this paper on Cell Death and Disease website (http://www.nature.com/cddis) 